\title{
BAT OCCUPANCY OF FORESTS AND MANAGED SAVANNA AND WOODLAND IN THE MISSOURI OZARK REGION
}

A Thesis
presented to
the Faculty of the Graduate School
at the University of Missouri-Columbia
In Partial Fulfillment
of the Requirements for the Degree
Master of Science
Mr. Frank R. Thompson, Thesis Supervisor
MAY 2013


(C) Copyright by Clarissa Starbuck 2013

All Rights Reserved 
The undersigned, appointed by the dean of the Graduate School, have examined the thesis entitled

\section{BAT OCCUPANCY OF FORESTS AND MANAGED SAVANNA AND WOODLAND IN THE MISSOURI OZARK REGION \\ presented by Clarissa Starbuck, a candidate for the degree of Master of Science, and hereby certify that, in their opinion, it is worthy of acceptance.}

Frank R. Thompson, Ph.D.

Matthew Gompper, Ph.D.

Dan Dey, Ph.D.

Sybill K. Amelon, Ph.D. 


\section{ACKNOWLEDGEMENTS}

I would like to thank my graduate committee for giving me so much help throughout this process. Dr. Frank Thompson has been very helpful and wonderfully available to answer my questions. Drs. Matt Gompper and Dan Dey provided great input and advice. I would like to thank Dr. Sybill Amelon very much for providing me this opportunity and for helping me pursue my love for bats from a young age. I would like to thank the U.S.D.A Forest Service for funding this project.

I would also like to thank Joe Amelon for helping me get field gear ready every year, for fixing gear when it is broken, for being the best field technician, and for providing excellent scones and other tasty treats. I had other field crew members who were also very helpful, and I couldn’t have done it without them. Sarah Pennington, Ben Zack, and Krista Bartel endured ticks and the heat of Missouri summers to set out many bat detectors.

I would also like to thank Kathryn Womack and Sarah Pennington for providing so much helpful input, advice, fun during conferences, and for coming with me on important chocolate excursions. Other graduate students in the Fisheries and Wildlife Sciences department also provided a valuable place for me to ask for help, get support, and relax. I also want to thank all of my family and friends who have provided their love and support for a very long time, especially my parents, Mike and Edie Starbuck. They have been so great at always being there and encouraging me to do what I love doing. 


\section{TABLE OF CONTENTS}

ACKNOWLEDGEMENTS........................................................

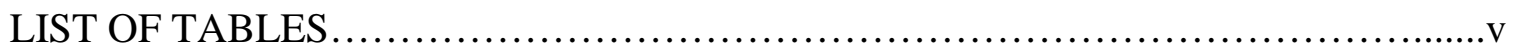

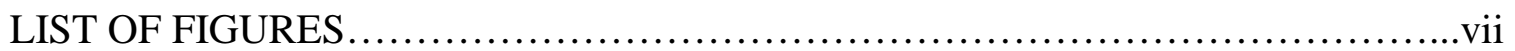

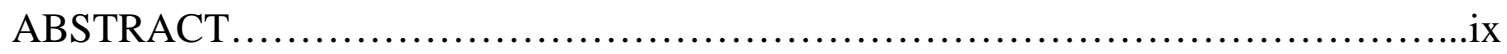

CHAPTER 1 - PROBABILITY OF DETECTION OF FIVE BAT SPECIES IN THE MISSOURI OZARK REGION

1. Abstract.............................................................1

2. Introduction...........................................................

a. Objectives..................................................4

3. Study Area...........................................................4

4. Methods

a. Locations of Survey Points.....................................6

b. Acoustic Detection.............................................6

c. Environmental Measurements.......................................8

d. Data Analysis...................................................8

5. Results................................................................

6. Discussion........................................................... 11

7. Literature Cited......................................................... 15

8. Appendix........................................................ 31 


\section{CHAPTER 2 - BAT OCCUPANCY OF FORESTS AND MANAGED SAVANNA}

\section{AND WOODLAND IN THE MISSOURI OZARK REGION}

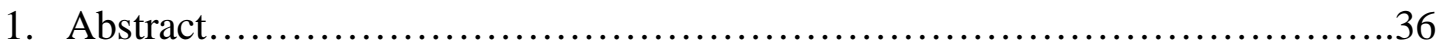

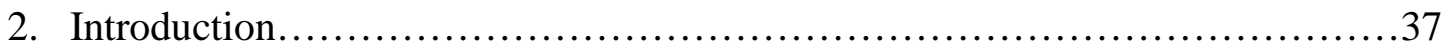

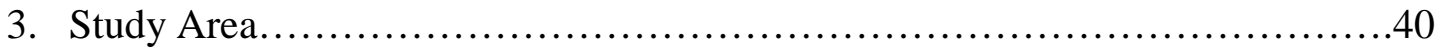

4. Methods

a. Locations of Sites and Survey Points..................................41

b. Acoustic Detection....................................................42

c. Vegetation and Landscape Measurements.............................43

d. Data Analysis.........................................................

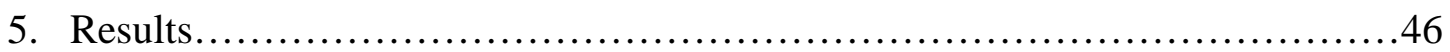

a. Big brown bat............................................................

b. Eastern red bat.................................................. 47

c. Northern long-eared bat............................................48

d. Evening bat...................................................... 48

e. Tri-colored bat..................................................... 49

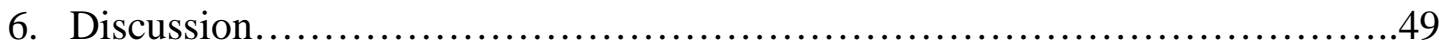

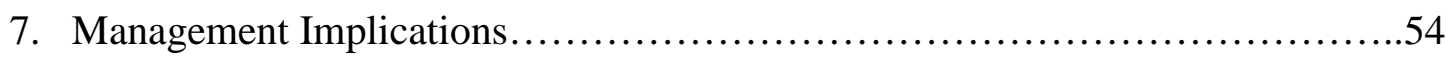

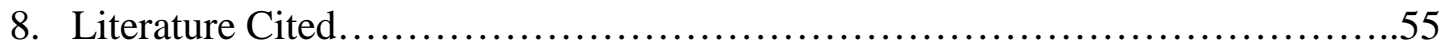

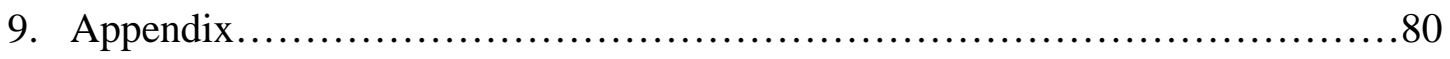




\section{LIST OF TABLES}

\section{CHAPTER 1}

Table 1. List of study areas, ownership, year(s) sampled, and number of points sampled per site in a study of bat occupancy in the Missouri Ozark Highlands,

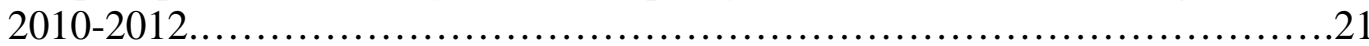

Table 2. The most supported models $(\Delta \mathrm{AIC}<4)$ for the probability of detection $(p)$, while holding occupancy effects $(\Psi)$ constant, in a study of site occupancy of 5 bat species in the Missouri Ozark Highlands, 2010-2012. We present number of model parameters (k), log likelihood (LogLik), Akaike's Information Criterion (AIC), delta AIC ( $\triangle \mathrm{AIC})$, and AIC weight $\left(w_{i}\right)$ for each model.................22

Table 3. Model averaged parameter estimates, unconditional standard errors (unconditional SE), and the upper and lower bounds for the $95 \%$ confidence intervals for the odds ratio for site occupancy models of 5 bat species in the

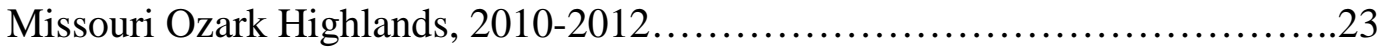

\section{CHAPTER 2}

Table 1. List of study areas, ownership, year(s) sampled, and number of points sampled per site in a study of bat occupancy in the Missouri Ozark Highlands, 2010-2012

Table 2. We present the minimum, maximum, mean, and standard error (SE) of each continuous covariate that was used in an occupancy study of 5 bat species in the Missouri Ozark Highlands, 2010-2012..................................65

Table 3. The most supported site occupancy models for the probability of detection $(p)$, while holding occupancy $(\Psi)$ effects constant, based on acoustic surveys of 5 bat species in the Missouri Ozark Highlands, 2010-2012. We present number of model parameters (k), log likelihood (LogLik), Akaike's Information Criterion (AIC), delta AIC ( $\triangle \mathrm{AIC})$, and AIC weight $\left(w_{i}\right)$ for each model........66

Table 4. The most supported site occupancy models $(\Delta \mathrm{AIC}<4)$ for the probability of site occupancy ( $\Psi$ ) for 5 bat species in the Missouri Ozark Highlands, 2010-2012. We present number of model parameters (k), log likelihood (LogLik), Akaike's Information Criterion (AIC), delta AIC ( $\triangle \mathrm{AIC}$ ), and AIC weight $\left(w_{i}\right)$ for each model. 
Table 5. Model averaged parameter estimates, unconditional standard errors (unconditional SE), and the upper and lower bounds for the 95\% confidence intervals in a study of site occupancy of 5 bat species in the Missouri Ozark

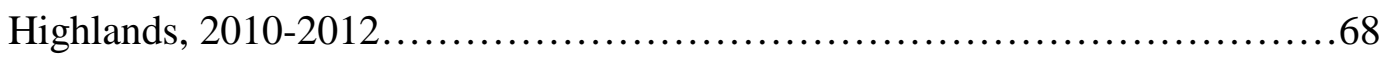




\section{LIST OF FIGURES}

\section{CHAPTER 1}

Figure 1. Probability of detection ( $p$ ) during acoustic surveys across the range of maximum hourly temperature for the big brown bat, eastern red bat, northern long-eared bat, and tri-colored bat in the Missouri Ozark Highlands, 20102012

Figure 2. Probability of detection ( $p$ ) during acoustic surveys across the range of relative humidity (\%) for the big brown bat, eastern red bat, northern long-eared bat, and tri-colored bat in the Missouri Ozark Highlands, 2010-2012............25

Figure 3. Probability of detection ( $p$ ) during acoustic surveys across the range of barometric pressure (in.Hg) for the big brown bat, eastern red bat, northern longeared bat, and tri-colored bat in the Missouri Ozark Highlands, 2010-2012.....26

Figure 4. Probability of detection ( $p$ ) during acoustic surveys across the range of Julian date for the big brown bat, eastern red bat, and evening bat in the Missouri Ozark Highlands, 2010-2012..........................................27

Figure 5. Probability of detection ( $p$ ) during acoustic surveys across the range of stand stocking (\%) for the big brown bat, eastern red bat, evening bat, and tricolored bat in the Missouri Ozark Highlands, $2010-2012 \ldots \ldots \ldots \ldots \ldots \ldots \ldots \ldots . .28$

Figure 6. Probability of detection ( $p$ ) during acoustic surveys across the range of distance to water $(\mathrm{m})$ for the northern long-eared bat in the Missouri Ozark

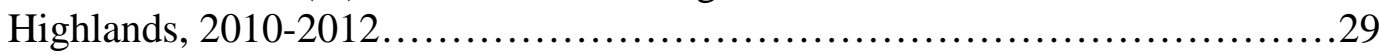

Figure 7. Probability of detection ( $p$ ) during acoustic surveys for 4 visits for the big brown bat, northern long-eared bat, and tri-colored bat in the Missouri Ozark

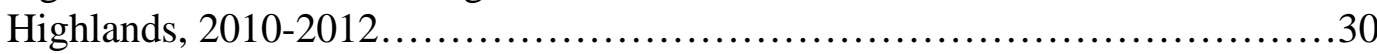

\section{CHAPTER 2}

Figure 1. Probability of occupancy ( $\Psi$ ) across the range of percent forest in a 16 $\mathrm{km}$ radius for the eastern red bat, northern long-eared bat, evening bat, and tricolored bat in the Missouri Ozark Highlands, 2010-2012.....................69

Figure 2. Probability of occupancy ( $\Psi$ ) across the range of percent urban land use in a $16 \mathrm{~km}$ radius for the eastern red bat, northern long-eared bat, evening bat, and tri-colored bat in the Missouri Ozark Highlands, 2010-2012..................70 
Figure 3. Probability of occupancy ( $\Psi$ ) across the range of saplings per acre for the big brown bat, eastern red bat, and northern long-eared bat in the Missouri Ozark Highlands, 2010-2012...........................................71

Figure 4. Probability of occupancy $(\Psi)$ across the range of poletimber per acre for the big brown bat, eastern red bat, and northern long-eared bat in the Missouri Ozark Highlands, 2010-2012...........................................72

Figure 5. Probability of occupancy ( $\Psi$ ) across the range of sawlogs per acre for the big brown bat, eastern red bat, and northern long-eared bat in the Missouri Ozark Highlands, 2010-2012..........................................73

Figure 6. Probability of occupancy ( $\Psi$ ) across the range of small stems per hectare for the big brown bat, eastern red bat, and northern long-eared bat in the Missouri Ozark Highlands, 2010-2012......................................74

Figure 7. Probability of occupancy ( $\Psi$ ) across the range of conifer basal area for the big brown bat and northern long-eared bat in the Missouri Ozark Highlands,

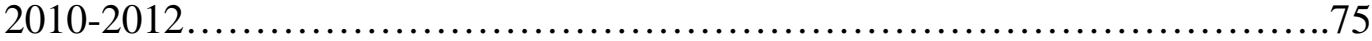

Figure 8. Probability of occupancy ( $\Psi$ ) across the range of distance to road in meters for the eastern red bat and northern long-eared bat in the Missouri Ozark

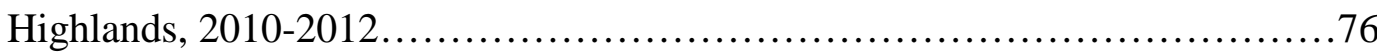

Figure 9. Probability of occupancy $(\Psi)$ across the range of percent stand stocking for the northern long-eared bat, evening bat, and tri-colored bat in the Missouri Ozark Highlands, 2010-2012...........................................77

Figure 10. Probability of occupancy $(\Psi)$ across the range of the number of fires in the last 10 years for the northern long-eared bat and evening bat in the Missouri

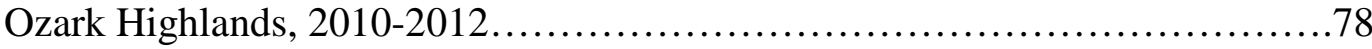

Figure 11. Probability of occupancy ( $\Psi$ ) across the range of distance to nearest water in meters for the eastern red bat and northern long-eared bat in the Missouri Ozark Highlands, 2010-2012...........................................79 


\title{
BAT OCCUPANCY OF FORESTS AND MANAGED SAVANNA AND WOODLAND IN THE MISSOURI OZARK REGION
}

\author{
Clarissa Starbuck \\ Dr. Frank R. Thompson III, Thesis Advisor
}

\begin{abstract}
Many Missouri land management agencies are restoring savannas and woodlands using prescribed fire and forest thinning, and information is needed on how wildlife species respond to these management activities. Our objectives were to 1 ) determine the relationship of temporal and environmental factors to the probability of detection $(p)$, and 2) determine how site occupancy ( $\Psi$ ) varies among savannas, woodlands, and forests as a function of vegetation structure and management history for 5 common bat species in the Missouri Ozark region: big brown bat (Eptesicus fuscus), eastern red bat (Lasiurus borealis), northern long-eared bat (Myotis septentrionalis), evening bat (Nycticeius humeralis), and tri-colored bat (Perimyotis subflavus). We identified sites that were actively managed for savanna and woodland conditions, and control areas on similar landforms that had no recent management and had succeeded to more closed canopy forest. We used Anabat detectors to survey bats during August 2010, May to July 2011, and May to June 2012. We fit single-season occupancy models for each species. We evaluated a priori hypotheses in an information theoretic approach by first evaluating factors affecting $p$ and then evaluating support for site occupancy models that included habitat and landscape effects. The probability of detecting bat species with acoustic detectors varied by species and was related to temperature, relative humidity, barometric
\end{abstract}


pressure, tree density, Julian date, distance to water, and visit. Generally, higher temperatures, lower humidity, lower tree density, and later dates in the summer resulted in higher $p$ for several bat species in the Missouri Ozark Highlands. The probability a site was occupied by foraging bats varied among species as a function of percent forest and urban land cover, stand stocking, distance to water and roads, number of fires in the last 10 years, and vegetative composition. It is important to consider the effects on $p$ when conducting acoustic surveys of bats. In general, vegetative structural conditions created by savanna and woodland restoration and management resulted in greater occupancy of the big brown bat, eastern red bat, evening bat, and tri-colored bat than was observed in mature, non-managed forest. 


\section{PROBABILTY OF DETECTION OF FIVE BAT SPECIES IN THE MISSOURI OZARK REGION}

\section{ABSTRACT}

Bats are difficult to study because of their small size, nocturnal behavior, and ability to fly. Acoustic detectors record the echolocation sounds made by bats and can be used to identify bat species. Our objective was to determine the relationships of temporal and environmental factors to the probability of detection $(p)$ of 5 common bat species in the Missouri Ozark region: big brown bat (Eptesicus fuscus), eastern red bat (Lasiurus borealis), northern long-eared bat (Myotis septentrionalis), evening bat (Nycticeius humeralis), and tri-colored bat (Perimyotis subflavus). We used Anabat detectors to survey bats at 23 points during August to September 2010, 148 points during May to July of 2011, and 171 points during May through June of 2012 and fit single-season occupancy models for each species. The probability of detecting bat species with acoustic detectors varied by species and was related to temperature, relative humidity, barometric pressure, tree density, Julian date, distance to water, and visit. Generally, higher temperatures, lower humidity, lower tree density, and later dates in the summer resulted in higher $p$ for several bat species in the Missouri Ozark Highlands.

Investigators can obtain more accurate estimates of occupancy and the effects of 
covariates on occupancy by using methods that account for imperfect detection and considering the factors that affect $p$ in their study design.

\section{INTRODUCTION}

Bats are difficult to study because of their small size, nocturnal behavior, and ability to fly. Bats can be captured with mist nets and harp traps, but these methods are labor intensive and may provide a biased sample of the bat community. Nets and traps are generally placed close to the ground so they may not adequately sample species that fly high above the ground (Lacki et al., 2007). Furthermore, individuals that are captured by nets and traps quickly learn to avoid them making it difficult to recapture individuals (Kunz and Anthony, 1977; Kunz and Brock, 1975; Larsen et al., 2007). Nets and traps can also be biased towards trapping juvenile bats (Kunz and Anthony (1977).

Acoustic detectors record the echolocation calls made by bats and can be used to identify bat species. Acoustic detectors can be used to detect the presence of species at a site and can be used in situations where nets and traps are difficult to use (Yates, 2006). Several factors affect whether or not a bat is detected by acoustic detectors. Sound is affected by environmental factors, which therefore will influence how far a bat call will travel and be detected (Lacki et al., 2007). Patriquin et al. (2003) found that the ability of an acoustic detector to detect a call was affected by whether a forest was open, thinned or unmanaged and if it was deciduous, coniferous, or mixed forest. Temperature and humidity affects how sound attenuates through space (Lawrence and Simmons, 1982). Higher relative humidity results in greater attenuation of high frequency sounds, and bats

generally echolocate at high frequencies ranging from 10 to $150 \mathrm{kHz}$ (Griffin, 1971). Bat 
species echolocate at different frequencies and intensities so the probability of detection by acoustic detectors will vary among species. Low frequency calls carry farther than high frequency calls (Griffin, 1971; Lacki et al., 2007; Weller, 2007) and high intensity calls carry further than low intensity calls (Lacki et al., 2007; O'Farrell and Gannon, 1999; Weller, 2007).

The probability of detection ( $p$ ) has been estimated for several species of bats as part of occupancy studies (Duchamp et al., 2006; Gorresen et al., 2008; Hein et al., 2009; Weller, 2008; Weller and Baldwin, 2012; Yates and Muzika, 2006). Programs MARK (Duchamp et al., 2006; Gorresen et al., 2008), PRESENCE (Hein et al., 2009; Weller, 2008; Yates and Muzika, 2006), and SAS (Weller and Baldwin, 2012) have been used to estimate $p$. Most studies used only acoustic methods to detect bats (Duchamp et al., 2006; Gorresen et al., 2008; Hein et al., 2009; Weller and Baldwin, 2012; Yates and Muzika, 2006), however Weller (2008) used acoustic and capture techniques. Gorresen et al. (2008) used 12 acoustic detectors set up in 2 arrays to detect bat calls over 11 and 12 nights to calculate $p$ and occupancy of Hawaiian hoary bats. Yates and Muzika (2006) used 1 acoustic detector at each site in southeastern Missouri with the night broken up into 4 visits to estimate $p$ and occupancy. Hein et al. (2009) also estimated $p$ for 6 species of bats in South Carolina at 32 pairs of sites. Weller and Baldwin (2012) estimated $p$ and site occupancy of bats at wind energy sites in southern California. Weller (2008) used both acoustic and capture methods to estimate $p$ and occupancy of bat species in the northwest United States. Duchamp et al. (2006) used a double-observer 
method using 2 acoustic detectors at each site to estimate $p$ of bats in Indiana and Missouri.

\section{Objectives}

The probability of detecting bats can vary among species, environmental conditions, and time. Therefore, we need better knowledge of the factors affecting detection so we address these factors in the design and analysis of acoustic surveys of bats. Our objective was to determine the relationships of species, environmental, and temporal factors to the probability of acoustic detection of 5 common bat species in the Missouri Ozark region: big brown bat (Eptesicus fuscus), eastern red bat (Lasiurus borealis), northern long-eared bat (Myotis septentrionalis), evening bat (Nycticeius humeralis), and tri-colored bat (Perimyotis subflavus). We hypothesized $p$ would vary by species and be related to temperature, relative humidity, barometric pressure, Julian date, distance to water, tree density, and time of night. We predicted that: $p$ would decrease as temperature and relative humidity increased due to the effects of sound attenuation, $p$ would increase with barometric pressure because of how pressure affects insects (the food source of all 5 bat species we studied), $p$ would decrease as tree density increased due to the interference of sound, $p$ would decrease as Julian date increased due to a greater numbers of insects and sound interference, $p$ would decrease as distance to water increased because bat activity is greater around water, and that $p$ would have a non-linear relationship with time of night because bats are crepuscular.

\section{STUDY AREA}


We conducted our study in the Missouri Ozark Highlands, which encompasses most of the southern half of the state. The landscape is gently rolling with some rugged upland areas, is characterized by carbonate bedrock, and includes many karst features such as sinkholes, caves, and spring-fed streams (Nigh and Schroeder, 2002). The spring-fed streams, caves, bluffs, glades, and forests of the Ozarks are home to many endemic species (Ethridge, 2009; Nigh and Schroeder, 2002). Annual average precipitation in the region ranged from $101.6 \mathrm{~cm}$ to $124.5 \mathrm{~cm}$, and average annual snowfall ranged from $25.4 \mathrm{~cm}$ to $50.8 \mathrm{~cm}$ (Nigh and Schroeder, 2002). The minimum average temperature in January ranged from $-8.3^{\circ} \mathrm{C}$ to $-5.5^{\circ} \mathrm{C}$, and the maximum average temperature in July ranged from $31.7^{\circ} \mathrm{C}$ to $32.8^{\circ} \mathrm{C}$ (Nigh and Schroeder, 2002). The rocky soils historically supported mainly glades and oak or oak-pine woodlands and forests. Flatter areas of the Ozarks historically supported gently rolling prairies and savannas. Pastures and urban areas now also make up parts of the Ozarks. Many of the open savannas and woodlands have increased in tree density because of the absence of fire (Nigh and Schroeder, 2002). The uplands in this landscape have white oak (Quercus alba), black oak (Q. velutina), scarlet oak (Q. coccinea), post oak (Q. stellata), blackjack oak (Q. marilandica), black hickory (Carya texana), and shortleaf pine (Pinus echinata); mesic slopes have greater proportions of white oak and associated red oak (Q. rubra), bitternut hickory (C. cordiformis), and flowering dogwood (Cornus florida); river birch (Betula nigra), eastern cottonwood (Populus deltoides), black willow (Salix nigra), American sycamore (Platanus occidentalis), and silver maple (Acer saccharinum) occur in riparian areas. Native openlands consist of bluestem (Andropogon gerardii, 
Schizachyrium scoparium) prairies and eastern red cedar (Juniperus virginiana) glades (McNab and Avers, 1994).

\section{METHODS}

\section{Locations of Survey Points}

This study was a part of a larger study on the effects of savanna and woodland restoration on birds, bats, and vegetation. We selected sites with a history of restoration activities, such as fire and thinning, by consulting with land managers from the Missouri Department of Conservation (MDC), the Missouri Department of Natural Resources (DNR), Mark Twain National Forest (MTNF), and The Nature Conservancy (TNC). Sites spanned a gradient in tree density from open savanna, to woodland, and forest. We located some bat survey points along point transects used for bird surveys. These transects were established by randomly placing a $250 \mathrm{~m}$ grid over a site and mapping a transect of 10-20 points spaced $250 \mathrm{~m}$ apart and at least $50 \mathrm{~m}$ from the edge of the managed site. We selected every $2^{\text {nd }}$ or $3^{\text {rd }}$ point along these transects for a total of up to 8 points per transect for bat survey. Other survey points were located consistent with an earlier bat study (Amelon, 2007) by randomly locating points that were $>250 \mathrm{~m}$ apart in managed savanna and woodland sites and non-managed forests using a GIS (ArcMap9.3.1, ESRI, Redlands, California).

\section{Acoustic Detection}

We surveyed bats using either Anabat II frequency division bat detectors and Zero-Crossing Analysis Interference Modules with Compact Flash memory storage (CF 
ZCAIM) or Anabat SD1 (combined Anabat detectors and CF ZCAIM unit; Titley

Electronics, Columbia, Missouri). We conducted bat surveys in August of 2010 and from May to July in both 2011 and 2012. We placed each detector at a point for at least two consecutive nights and set it to record from 1800 to 0600 each night. We placed detectors and a 12-volt battery in waterproof Pelican cases to protect them from weather and animals. The detector microphone stuck out of the case through a hole and into a 45 degree PVC elbow that protected the microphone and directed the detection cone upward; this type of weatherproofing does not affect the number and quality of calls obtained (Britzke et al., 2010). We placed detectors on the ground with the microphone oriented in the direction of the least amount of ground vegetation to reduce obstruction of sound as well as the amount of insect noise collected. We calibrated the sensitivity of all detectors to standardize the detection distance and the sampling area as described by Livengood (2003).

We downloaded call files from the compact flash (CF) card to a computer and analyzed files with AnalookW (Corben, 2007) to identify a species. We used digital filters to eliminate ambient and insect noise and low quality sequences and those with less than 5 call pulses (Amelon, 2007). We compared the collected calls to a library of known calls and published information on quantitative call characteristics to identify calls to species. To distinguish between species, we looked at the minimum frequency, duration, characteristic frequency, initial slope, characteristic slope, cadence, and consistency of calls. We recorded the detection (1) or non-detection (0) of each species 
for two periods each night (1800-0000 and 0000-0600); therefore the detection history for each site consisted of four values representing the two periods for two consecutive nights.

\section{Environmental Measurements}

We measured or compiled data for factors hypothesized to affect detection for each survey. We used a 10 factor prism to sample trees $>10 \mathrm{~cm}$ diameter at breast height (DBH) at each point and calculate percent stand stocking (Gingrich, 1967). We classified vegetation type as forest or savanna/woodland by percent stand stocking. Points with stand stocking $0 \%$ to $80 \%$ were considered savanna/woodland, and points with $>80 \%$ stocking were considered forest. We measured the distance of each point to the nearest water source in meters using ArcMap 9.3.1 and a statewide hydrography layer that included large rivers and small creeks (National Hydrography Dataset Plus, U.S. Environmental Protection Agency and U.S. Geological Survey, 2005). We compiled weather data from the National Climatic Data Center for the stations closest to each site, which included Rolla, Kaiser Lake Ozark, Farmington, Cape Girardeau, West Plains, Springfield, Whiteman Air Force Base, Spirit of St. Louis Airport, and Poplar Bluff. We calculated maximum dry bulb temperature $\left({ }^{\circ} \mathrm{C}\right)$, maximum relative humidity $(\%)$, and average barometric pressure (in. $\mathrm{Hg}$ ) for each of the 4 sampling periods from hourly values.

\section{Data Analysis}

We used single-season occupancy models (Royle and Nichols, 2003) in the program PRESENCE 5.3 to fit models for each species. We considered the effects of 
visit, temperature, relative humidity, barometric pressure, Julian date, distance to nearest water source, and stand stocking on $p$. We considered a set of candidate models consisting of these covariates individually and in all additive combinations, except that temperature, relative humidity, and barometric pressure always occurred together to represent a weather effect; which resulted in 33 models for each species. Occupancy models consider effects on $p$ as well as effects on occupancy. Our focus was on the factors affecting $p$, but since we thought occupancy likely varied by vegetation type, we included vegetation type (forest or savanna/woodland) as an occupancy effect in all models.

We used Akaike's Information Criteria (AIC) to select the model that best explained the empirical data. We drew inference from a confidence set of models with $\Delta \mathrm{AIC}<4$, but did not consider models with uninformative parameters where the addition of a parameter did not overcome the 2 AIC point penalty for the parameter (Arnold, 2010). We model averaged to obtain the average coefficient, unconditional standard error, odds ratio, and 95\% confidence interval for the odds ratio for each covariate (Burnham and Anderson, 2002). We demonstrated effects of covariates by plotting the average of predicted detection probabilities for the 4 visits across the range of covariates while holding other covariates at their mean. We plotted model averaged predictions for 7 points evenly spaced from $1^{\text {st }}$ to $99^{\text {th }}$ percentile of a supported covariate to exclude outliers.

\section{RESULTS}


We conducted surveys at 369 points across 26 sites, of which 342 points had detectors that successfully collected data (Table 1). The dates of surveys ranged from 15 May - 1 September (Julian date 135-244). We detected all 5 focal species and obtained 565,624 call files across all years and sites. Across the dates and times of our surveys, temperature, relative humidity, and barometric were $10-30.6{ }^{\circ} \mathrm{C}, 50-100 \%$, and 28.315 - 29.678 in. Hg, respectively. Stand stocking ranged $0-178 \%$ and distance to water 0 $662.7 \mathrm{~m}$ across the points surveyed.

We fitted models for all species with the exception that models with weather effects would not converge properly for evening bat, so we did not consider weather effects for this species. The top models for $p$ varied by species (Table 2). All bat species (except the evening bat) included weather in the top model. The top model for big brown bats included visit, weather, Julian date, and stand stocking and average $p=0.42$. The top model for eastern red bats included weather, Julian date, and stand stocking and average $p=0.74$. The top model for northern long-eared bats included visit, weather, and distance to water and average $p=0.50$. The top model for evening bats included Julian date and stand stocking and average $p=0.34$. The top model for tri-colored bats included visit, weather, and stand stocking and average $p=0.59$ (Table 2).

Temperature was positively related to $p$ for the big brown bat, eastern red bat, northern long-eared bat, and tri-colored bat and the confidence limits for coefficients did not include 0 except for the northern long-eared bat (Table 3, Figure 1). Relative humidity was positively related to $p$ for the big brown bat, eastern red bat, and the tricolored bat, negatively related to $p$ for the northern long-eared bat (Figure 2) and the 
confidence limits for coefficients did not include 0 (Table 3). Barometric pressure was positively related to $p$ of northern long-eared bats and tri-colored bats, and negatively related to $p$ of the eastern red bat and the big brown bat (Figure 3); the confidence limits for coefficients did not include 0 except for the big brown bat (Table 3). Julian date was negatively related to $p$ for the big brown bat, eastern red bat, and evening bat (Figure 4); the confidence intervals for coefficients did not include 0 (Table 3).

Stand stocking was negatively related to $p$ for the big brown bat, eastern red bat, evening bat, and tri-colored bat (Figure 5). The confidence intervals for coefficients for stocking did not include 0 except for the evening bat (Table 3). Distance to water was positively related to $p$ for the northern long-eared bat (Figure 6) and the confidence interval did not include 0 (Table 3).

The probability of detection was affected by visit for 3 of 5 species. Visits 2 and 4 had greater $p$ than visits 1 and 3 for the big brown bat, northern long-eared bat, and the tri-colored bat (Figure 7). The confidence intervals for coefficients for all visits did include 0 except for the northern long-eared bat (Table 3).

\section{DISCUSSION}

Environmental factors affected acoustic detection of bat species, and many of these effects differed among bat species. Temperature had a positive effect on the detection of 4 of 5 species, which was contrary to our hypothesis that it would have a negative effect. Knudsen (1946) showed that absorption of sound by air was higher at 55 ${ }^{\circ} \mathrm{C}$ than at $20^{\circ} \mathrm{C}$, but our maximum temperature was only $30.6^{\circ} \mathrm{C}$. However, warmer 
temperatures have shown an increase in insect activity than at cooler temperatures (Womack, 2011), and more insect activity results in greater bat activity (Fukui et al., 2006; Womack, 2011). Greater bat activity results in greater detections of bats by the detector, so even if there was more absorption of sound by the warmer air, the greater bat activity may have resulted in a positive relationship between $p$ and temperature.

Relative humidity had a positive effect on $p$ for 3 of the 4 species affected by humidity; only $p$ for the northern long-eared bat was affected negatively by relative humidity. The northern long-eared bat was the only Myotis species in our study, and this species generally echolocates at a higher frequency than the other 3 species affected. The frequency of northern long-eared bat calls is as great as $60-126 \mathrm{kHz}$ (Caceres and Barclay, 2000), and sounds in this high frequency range are more affected by high humidity than lower frequency sounds (Griffin, 1971). Big brown bats, eastern red bats, and tri-colored bats echolocate at frequencies from about 25-60 kHz. At $60 \mathrm{kHz}$, atmospheric attenuation of sound starts to decrease after only about $50 \%$ humidity at 25 ${ }^{\circ} \mathrm{C}$, and even less for lower frequencies (Griffin, 1971). At the temperatures and humidities we observed, only detection of bats that produce very high frequency calls, like the northern long-eared bat, were negatively affected by humidity.

The effects of barometric pressure on $p$ varied among species. Only the eastern red bat had a strong negative correlation with barometric pressure. Insect activity, and as a result bat activity, may be negatively related to barometric pressure and bats may monitor barometric pressure to determine when to forage (Paige, 1995). However, we found that barometric pressure was positively related to $p$ for northern long-eared and tri- 
colored bats. Kerns et al. (2005) found that barometric pressure had a positive correlation with bat fatality rates at 2 wind farms in Pennsylvania and West Virginia, suggesting that bat activity was positively related to barometric pressure. This correlates with higher barometric pressure and more bat activity after storm fronts pass through (Kerns et al., 2005). Wolcott and Vulinec (2012) also found an increase in bat activity with an increase in barometric pressure at woodland/farmland interfaces in Delaware. The effect of barometric pressure on bat activity, and therefore bat detection, may vary greatly from species to species.

Julian date negatively affected 3 bat species in our study. Our first season in 2010 included later dates than the second two years. In 2010, we surveyed bats in late August which could coincide with the beginning of migration and fall swarming which would decrease $p$ as bats began moving away from our study areas. The next two survey seasons ran from May to July which is during the maternity season, and juveniles would begin to fly toward the later part of this period, which would hypothetically increase $p$. However, we saw no increase in $p$ over the range of all Julian dates for any species. An increase of insects later in the summer could cause more interference with the detectors, causing $p$ to decrease as Julian date increased over the summer which is what we hypothesized.

We found support for our hypothesis that $p$ would be negatively related to the amount of stand stocking for 4 of 5 species. Patriquin et al. (2003) found the ability to detect $40 \mathrm{kHz}$ sounds was similar in 100\% versus 50\% stocked forests, however attenuation of $25 \mathrm{kHz}$ sounds was greater in $100 \%$ versus $50 \%$ stocked forests. So, bats 
that echolocate at a lower frequency might be harder to detect in a dense forest than bats that echolocate at a higher frequency. The effect was greatest for the big brown bat, eastern red bat, evening bat, and tri-colored bat. Stand stocking had a very small positive effect on $p$ for the northern long-eared bat, which echolocates at a higher frequency than the other species.

We expected there to be more bat activity, and hence greater $p$, at sites closer to the water, making it easier to detect a bat, but the opposite was true for the northern longeared bat. We found distance to water only affected $p$ for the northern long-eared bat, and $p$ increased as distance to water increased. Amelon (2007) found that the presence of a water source positively affected the detection of 8 species of bats in Missouri. However, she subjectively tried to put detectors near water, and all of our points were randomly selected. It could be that we did not have enough detectors close enough to a water source to detect an effect on $p$, but our estimates of $p$ for each species were similar to Amelon (2007).

The effect of visit was supported for 3 of 5 species. The effect had a similar pattern for all 3 species. The probability of detection was greater for 0000 - 0600 (visits 2 and 4) than 1800 - 0000 (visits 1 and 3). If $p$ is related to bat activity, this pattern is contrary to some reported patterns in bat activity (Broders et al., 2003; Hayes, 1997; Kunz, 1973; Kunz and Brock, 1975; O'Farrell and Bradley, 1970). Kunz and Brock (1975) found two peaks of bat activity, right after dusk and right before dawn, but the peak right after dusk was much greater. However, Parsons et al. (2003) found that bat activity was highest 6 and 7 hours after sunset during swarming in England. They 
suggested that this was due to the fact that bats were traveling long distances to the swarming site, and so the bats were not in the area until later in the night. Although our study did not occur during swarming, perhaps many of these bats were traveling longer distances from their roost site to their foraging site.

The evening bat was, overall, the least detectable of the 5 species studied, and the eastern red bat was the most detectable. Eastern red bats are common in Missouri, so it would make sense for this species to have a high $p$. Yates (2006) found that the tricolored bat (eastern pipistrelle) and eastern red bat had a greater $p$ than northern longeared bats, Indiana bats (Myotis sodalis), and gray bats (M. grisescens), which is consistent with our results.

Acoustic detection is a valuable tool for surveying bat occurrence, but it is important to realize that the $p$ is $<1$. Knowing what factors affect $p$ when designing a study will produce more accurate results in occupancy studies. We found that the ability to detect bats with Anabat detectors varied by species and was affected by temperature, humidity, stand stocking, and Julian date. Generally, higher temperatures, lower humidity, lower tree density, and later dates in the summer result in higher $p$ for several bat species in the Missouri Ozark Highlands. Investigators can obtain more accurate estimates of occupancy and the effects of covariates on occupancy by using methods that account for imperfect detection and considering the factors that affect $p$ in their study design.

\section{LITERATURE CITED}


Amelon, S. K. 2007. Multi-scale factors influencing detection, site occupancy and resource use by foraging bats in the Ozark Highlands of Missouri, University of Missouri, Columbia, Missouri.

Arnold, T. W. 2010. Uninformative parameters and model selection using Akaike's Information Criterion. Journal of Wildlife Management 74: 1175-1178.

Britzke, E. R., B. A. Slack, M. P. Armstrong, and S. C. Loeb. 2010. Effects of orientation and weatherproofing on the detection of bat echolocation calls. Journal of Fish and Wildlife Management 1: 136-141.

Broders, H. G., G. M. Quinn, and G. J. Forbes. 2003. Species status, and the spatial and temporal patterns of activity of bats in southwest Nova Scotia, Canada. Northeastern Naturalist 10: 383-398.

Burnham, K. P., and D. R. Anderson. 2002. Model selection and multi-model inference: a practical information-theoretic approach. Springer.

Caceres, M. C., and R. M. R. Barclay. 2000. Myotis septentrionalis. Mammalian Species 634: 1-4.

Corben, C. 2007. Anabat. http://users.lmi.net/corben/anabat.htm Accessed February 17 2011.

Duchamp, J. E., M. Yates, R. M. Muzika, and R. K. Swihart. 2006. Estimating probabilities of detection for bat echolocation calls: An aplication of the doubleobserver method. Wildlife Society Bulletin 34: 408-412.

Ethridge, M. 2009. The Ozark Highlands: U.S. Geological Fact Sheet 2009-3065.

Fukui, D., M. Murakami, S. Nakano, and T. Aoi. 2006. Effect of emergent aquatic insects on bat foraging in a riparian forest. The Journal of animal ecology 75: 1252-1258. 
Gingrich, S. F. 1967. Measuring and evaluating stocking and stand density in upland hardwood forests in the Central States. Forest Science 13: 38-53.

Gorresen, P. M., A. C. Miles, C. M. Todd, F. J. Bonaccorso, and T. J. Weller. 2008. Assessing bat detectability and occupancy with multiple automated echolocation detectors. Journal of Mammalogy 89: 11-17.

Griffin, D. R. 1971. The importance of atmospheric attenuation for the echolocation of bats (Chiroptera). Animal Behavior 19: 55-61.

Hayes, J. P. 1997. Temporal variation in activity of bats and the design of echolocationmonitoring studies. Journal of Mammalogy 78: 514-524.

Hein, C., S. Castleberry, and K. Miller. 2009. Site-occupancy of bats in relation to forested corridors. Forest Ecology and Management 257: 1200-1207.

Kerns, J., W. P. Erickson, and E. B. Arnett. 2005. Bat and bird fatality at wind energy facilities in Pennsylvania and West Virginia. In: E. B. Arnett (ed.) Relationships between bats and wind turbines in Pennsylvania and West Virginia: An assessment of fatality search protocols, patterns of fatality, and behavioral interactions with wind turbines. A final report submitted to the Bats and Wind Energy Cooperative. p 24-95. Bat Conservation International, Austin, Texas, USA.

Knudsen, V. O. 1946. The propagation of sound in the atmosphere - attenuation and fluctuations. Journal of the Acoustical Society of America 18: 90-96.

Kunz, T. H. 1973. Resource utilization: temporal and spatial components of bat activity in central Iowa. Journal of Mammalogy 54: 14-32. 
Kunz, T. H., and E. L. P. Anthony. 1977. On the efficiency of the Tuttle bat trap. Journal of Mammalogy 58: 309-315.

Kunz, T. H., and C. E. Brock. 1975. A comparison of mist nets and ultrasonic detectors for monitoring flight activity of bats. Journal of Mammalogy 56: 907-911.

Lacki, M. J., S. K. Amelon, and M. D. Baker. 2007. Foraging Ecology of Bats in Forests. In: M. J. Lacki, J. P. Hayes and A. Kurta (eds.) Bats in Forests: Conservation and Management. p 83-127. The Johns Hopkins University Press, Baltimore, Maryland.

Larsen, R. J. et al. 2007. Mist netting bias, species accumulation curves, and the rediscovery of two bats on Montserrat (Lesser Antilles). Acta Chiropterologica 9: 423-435.

Lawrence, B. D., and J. A. Simmons. 1982. Measurements of atmospheric attenuation at ultrasonic frequencies and the significance for echolocation by bats. Journal of the Acoustical Society of America 71: 585-590.

Livengood, K. 2003. Anabat zone of reception and the sources of variation in detection zone, University of Missouri, Columbia, Missouri.

McNab, W. H., and P. E. Avers. 1994. Ecological subregions of the United States, section descriptions Administrative Publication WO-WSA-5. U.S. Department of Agriculture, Washington, D.C., USA.

Nigh, T. A., and W. A. Schroeder. 2002. Atlas of Missouri Ecoregions. The Conservation Commission - State of Missouri.

O'Farrell, M. J., and W. G. Bradley. 1970. Activity patterns of bats over a desert spring. Journal of Mammalogy 51: 18-26. 
O'Farrell, M. J., and W. L. Gannon. 1999. A comparison of acoustic versus capture techniques for the inventory of bats. Journal of Mammalogy 80: 24-30.

Paige, K. N. 1995. Bats and barometric pressure: conserving limited energy and tracking insects from the roost. Functional Ecology 9: 463-467.

Parsons, K. N., G. Jones, and F. Greenaway. 2003. Swarming activity of temperate zone microchiropteran bats: effects of season, time of night and weather conditions. Journal of Zoology 261: 257-264.

Patriquin, K. J., L. K. Hogberg, B. J. Chruszcz, and R. M. R. Barclay. 2003. The influence of habitat structure on the ability to detect ultrasound using bat detectors. Wildlife Society Bulletin 31: 475-481.

Royle, J. A., and J. D. Nichols. 2003. Estimating abundance from repeated presenceabsence data or point counts. Ecology 84: 777-790.

Weller, T. J. 2007. Assessing population status of bats in forests: challenges and opportunities. In: M. J. Lacki, J. P. Hayes and A. Kurta (eds.) Bats in Forests: Conservation and Management. p 263-291. The Johns Hopkins University Press, Baltimore, Maryland.

Weller, T. J. 2008. Using occupancy estimation to assess the effectiveness of a regional multiple-species conservation plan: Bats in the Pacific Northwest. Biological Conservation 141: 2279-2289.

Weller, T. J., and J. A. Baldwin. 2012. Using echolocation monitoring to model bat occupancy and inform mitigations at wind energy facilities. The Journal of Wildlife Management 76: 619-631. 
Wolcott, K. A., and K. Vulinec. 2012. Bat Activity at Woodland/Farmland Interfaces in Central Delaware. Northeastern Naturalist 19: 87-98.

Womack, K. M. 2011. Factors affecting insect prey and Indiana bat activity in Missouri during the maternity season, University of Missouri, Columbia, Missouri.

Yates, M. D. 2006. Detection and modeling of bat species occupancy at multiple scales across a forested landscape in southeastern Missouri, University of Missouri, Columbia, Missouri.

Yates, M. D., and R. M. Muzika. 2006. Effect of forest structure and fragmentation on site occupancy of bat species in Missouri Ozark forests. Journal of Wildlife Management 70: 1238-1248. 
Table 1. List of study areas, ownership, year(s) sampled, and number of points sampled per site in a study of bat occupancy in the Missouri Ozark Highlands, 2010-2012.

\begin{tabular}{lrrr}
\hline Study Area & Ownership & $\begin{array}{r}\text { Year(s) } \\
\text { Sampled }\end{array}$ & $\begin{array}{r}\text { Number of } \\
\text { Points }\end{array}$ \\
\hline Lead Mine Conservation Area & MDC & 2010 & 9 \\
Sunklands Conservation Area & MDC & 2010 & 9 \\
Little Black Conservation Area & MDC & 2011 & 8 \\
Ha Ha Tonka State Park & DNR & 2011 & 10 \\
Lake of the Ozarks State Park & DNR & 2011 & 16 \\
Knob Noster State Park & DNR & 2011 & 12 \\
Rocky Creek Conservation Area & MDC & 2011 & 4 \\
Western Star Flatwoods & MTNF & 2011 & 10 \\
Caney Mountain Conservation Area & MDC & 2011 & 15 \\
Drury-Mincy Conservation Area & MDC & 2011 & 11 \\
Bluff Springs Conservation Area & MDC & 2011 & 8 \\
Indian Trail Conservation Area & MDC & 2011 & 12 \\
St. Joe State Park & DNR & 2011 & 16 \\
White Ranch Conservation Area & MDC & 2011 & 7 \\
Chilton Creek & TNC & 2011 & 7 \\
Cuivre River State Park & DNR & 2012 & 19 \\
Handy & MTNF & 2012 & 16 \\
Cane Ridge & MTNF & 2012 & 14 \\
Peck Ranch Conservation Area & MDC & 2012 & 28 \\
St. Francois State Park & DNR & 2012 & 14 \\
Mark Twain Glade Top & MTNF & 2012 & 13 \\
Ava & MTNF & 2012 & 12 \\
Big Creek & MTNF & 2012 & 18 \\
Three Sisters & MTNF & 2012 & 10 \\
Bennett Springs State Park & DNR & 2010,2012 & 19 \\
Pine Knot & MTNF & 2011,2012 & 25 \\
\hline
\end{tabular}


Table 2. The most supported models $(\Delta \mathrm{AIC}<4)$ for the probability of detection $(p)$, while holding occupancy effects $(\Psi)$ constant, in a study of site occupancy of 5 bat species in the Missouri Ozark Highlands, 2010-2012. We present number of model parameters (k), log likelihood (LogLik), Akaike's Information Criterion (AIC), delta AIC $(\triangle \mathrm{AIC})$, and AIC weight $\left(w_{i}\right)$ for each model.

\begin{tabular}{|c|c|c|c|c|c|}
\hline Model by species & $\mathrm{k}$ & LogLike & AIC & $\Delta \mathrm{AIC}$ & $w_{i}$ \\
\hline \multicolumn{6}{|l|}{ Big brown bat } \\
\hline$\Psi$ (habitat),p(v,weather,date,stocking) & 12 & 1532.03 & 1556.03 & 0 & 0.554 \\
\hline \multicolumn{6}{|l|}{ Eastern red bat } \\
\hline$\Psi$ (habitat),p(weather,date,stocking) & 9 & 1493.93 & 1511.93 & 0 & 0.519 \\
\hline \multicolumn{6}{|l|}{ Northern long-eared bat } \\
\hline$\Psi$ (habitat), $p$ (v,weather,water) & 11 & 1523.6 & 1545.6 & 0 & 0.4592 \\
\hline \multicolumn{6}{|l|}{ Evening bat } \\
\hline$\Psi$ (habitat),p(date,stocking) & 6 & 793.28 & 805.28 & 0 & 0.2709 \\
\hline$\Psi$ (habitat),p(date) & 5 & 795.68 & 805.68 & 0.4 & 0.2218 \\
\hline$\Psi$ (habitat),p(stocking) & 5 & 797.16 & 807.16 & 1.88 & 0.1058 \\
\hline \multicolumn{6}{|l|}{ Tri-colored bat } \\
\hline$\Psi$ (habitat),p(v,weather,stocking) & 11 & 1648.12 & 1670.12 & 0 & 0.2818 \\
\hline$\Psi$ (habitat), $p$ (weather,stocking) & 8 & 1656.05 & 1672.05 & 1.93 & 0.1074 \\
\hline
\end{tabular}


Table 3. Model averaged parameter estimates, unconditional standard errors (unconditional SE), and the upper and lower bounds for the 95\% confidence intervals for the odds ratio for site occupancy models of 5 bat species in the Missouri Ozark Highlands, 2010-2012.

\begin{tabular}{|c|c|c|c|c|}
\hline Variables by species & Coefficient & unconditional SE & lower bound & upper bound \\
\hline \multicolumn{5}{|l|}{ Big brown bat } \\
\hline V1 & 0.9257 & 0.9964 & -1.0273 & 2.8787 \\
\hline V2 & 1.8620 & 0.9675 & -0.0343 & 3.7583 \\
\hline V3 & 0.8201 & 1.0007 & -1.1414 & 2.7815 \\
\hline V4 & 1.6598 & 0.9672 & -0.2360 & 3.5556 \\
\hline Temp & 0.1241 & 0.0180 & 0.0888 & 0.1594 \\
\hline RH & 0.0315 & 0.0031 & 0.0254 & 0.0376 \\
\hline BP & -0.0345 & 0.0287 & -0.0907 & 0.0217 \\
\hline JulDate & -0.0351 & 0.0010 & -0.0372 & -0.0331 \\
\hline STANDSTOCK & -0.0048 & 0.0015 & -0.0078 & -0.0017 \\
\hline \multicolumn{5}{|l|}{ Eastern red bat } \\
\hline Temp & 0.0472 & 0.0159 & 0.0160 & 0.0784 \\
\hline RH & 0.0250 & 0.0043 & 0.0166 & 0.0334 \\
\hline $\mathrm{BP}$ & -0.5177 & 0.0349 & -0.5862 & -0.4493 \\
\hline JulDate & -0.0170 & 0.0012 & -0.0194 & -0.0147 \\
\hline STANDSTOCK & -0.0096 & 0.0015 & -0.0127 & -0.0066 \\
\hline \multicolumn{5}{|c|}{ Northern long-eared bat } \\
\hline V1 & -16.8830 & 0.8618 & -18.5722 & -15.1938 \\
\hline $\mathrm{V} 2$ & -16.6657 & 0.8464 & -18.3245 & -15.0068 \\
\hline V3 & -17.2942 & 0.8658 & -18.9912 & -15.5973 \\
\hline V4 & -16.2863 & 0.8533 & -17.9588 & -14.6138 \\
\hline Temp & 0.0137 & 0.0192 & -0.0239 & 0.0513 \\
\hline RH & -0.0202 & 0.0039 & -0.0280 & -0.0125 \\
\hline BP & 0.6156 & 0.0271 & 0.5625 & 0.6687 \\
\hline dist2water & 0.0017 & 0.0004 & 0.0009 & 0.0024 \\
\hline \multicolumn{5}{|l|}{ Evening bat } \\
\hline JulDate & -0.0096 & 0.0044 & -0.0182 & -0.0011 \\
\hline STANDSTOCK & -0.0033 & 0.0036 & -0.0103 & 0.0037 \\
\hline \multicolumn{5}{|l|}{ Tri-colored bat } \\
\hline V1 & -6.8795 & 3.8920 & -14.5078 & 0.7488 \\
\hline V2 & -6.5524 & 3.7089 & -13.8219 & 0.7171 \\
\hline V3 & -6.8876 & 3.8974 & -14.5265 & 0.7513 \\
\hline V4 & -6.5019 & 3.6820 & -13.7186 & 0.7148 \\
\hline Temp & 0.0507 & 0.0228 & 0.0061 & 0.0954 \\
\hline $\mathrm{RH}$ & 0.0099 & 0.0035 & 0.0030 & 0.0167 \\
\hline $\mathrm{BP}$ & 0.2779 & 0.0309 & 0.2174 & 0.3385 \\
\hline STANDSTOCK & -0.0102 & 0.0016 & -0.0134 & -0.0070 \\
\hline
\end{tabular}



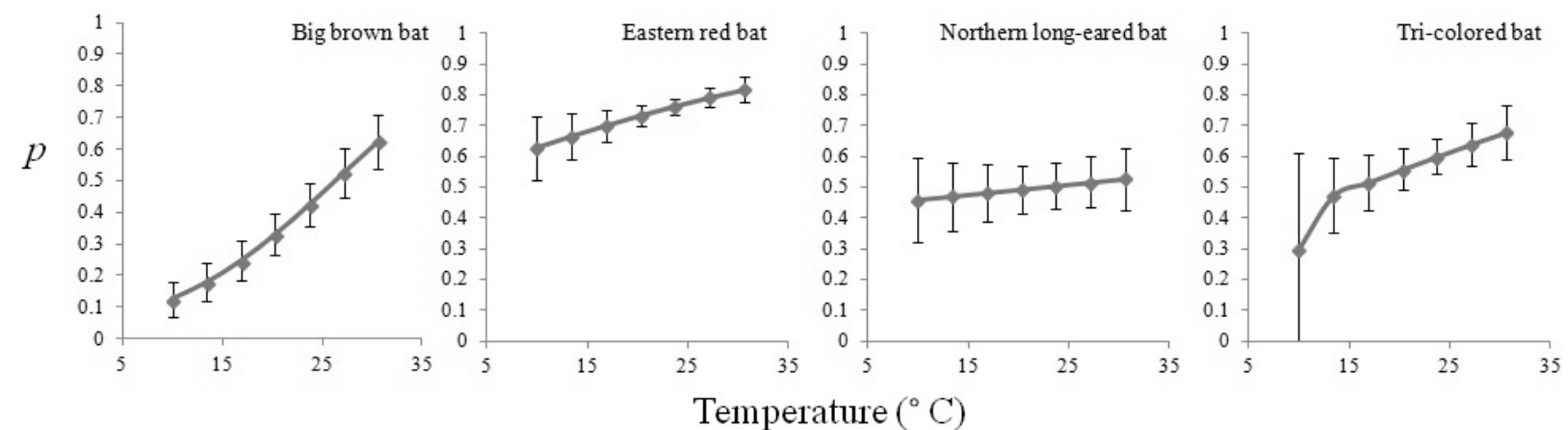

Figure 1. Probability of detection ( $p$ ) during acoustic surveys across the range of maximum hourly temperature for the big brown bat, eastern red bat, northern long-eared bat, and tri-colored bat in the Missouri Ozark Highlands, 2010-2012. 

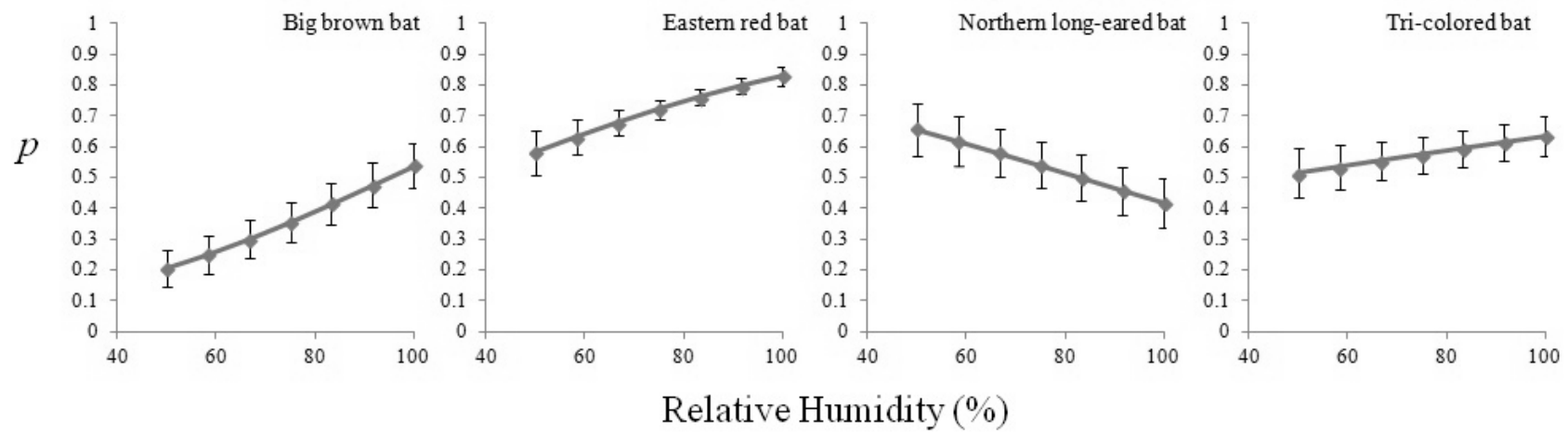

Figure 2. Probability of detection ( $p$ ) during acoustic surveys across the range of relative humidity (\%) for the big brown bat, eastern red bat, northern long-eared bat, and tricolored bat in the Missouri Ozark Highlands, 2010-2012. 

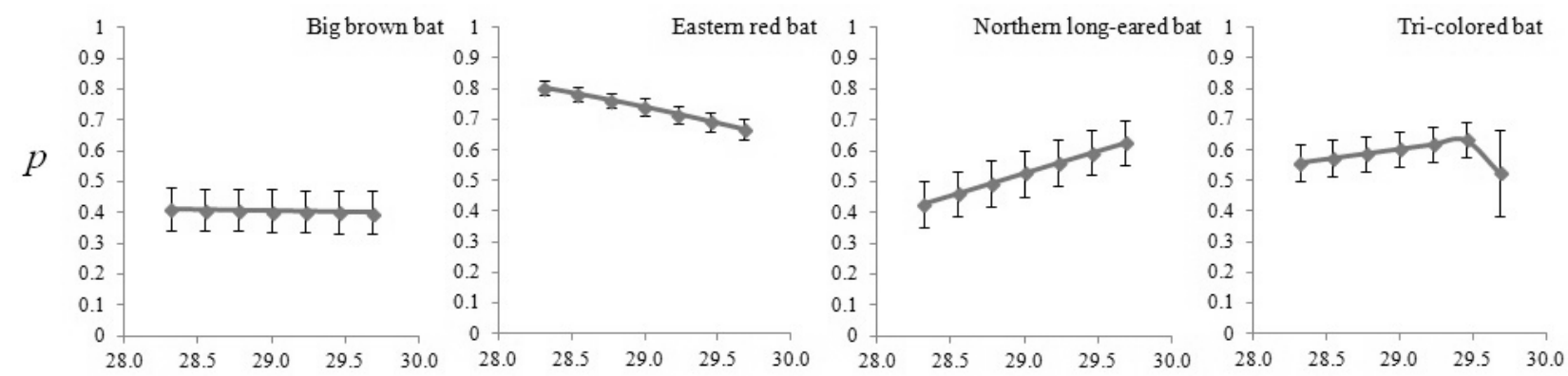

Barometric Pressure (in. $\mathrm{Hg}$ )

Figure 3. Probability of detection ( $p$ ) during acoustic surveys across the range of barometric pressure (in.Hg) for the big brown bat, eastern red bat, northern long-eared bat, and tri-colored bat in the Missouri Ozark Highlands, 2010-2012. 

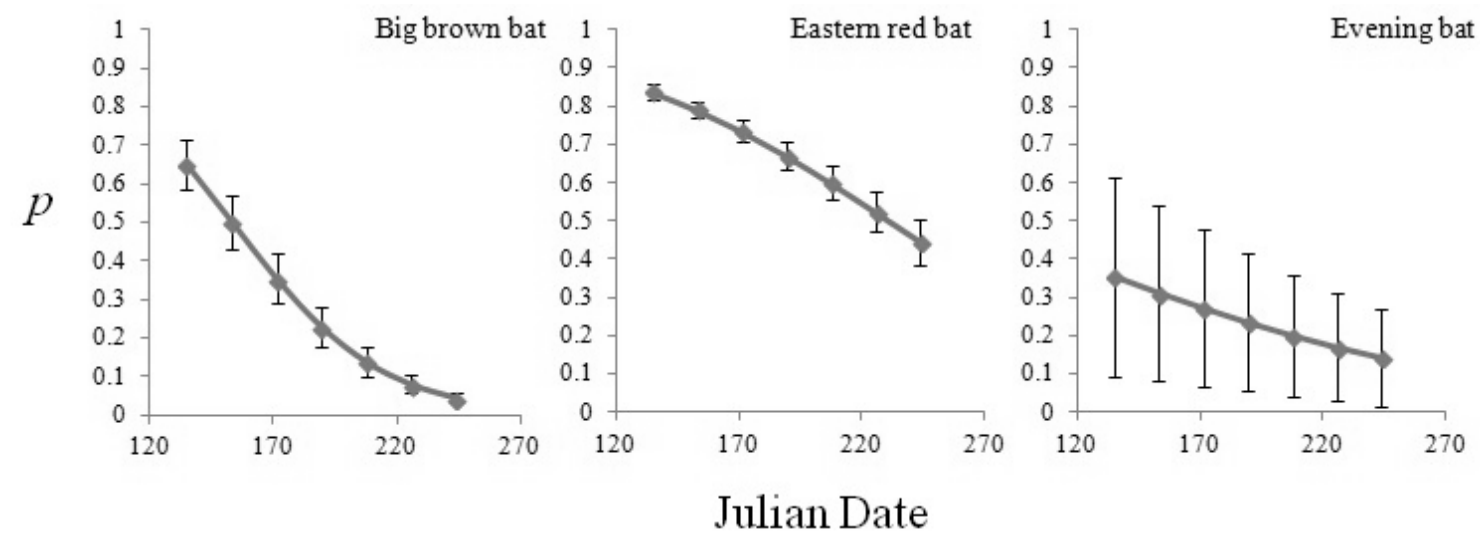

Figure 4. Probability of detection ( $p$ ) during acoustic surveys across the range of Julian date for the big brown bat, eastern red bat, and evening bat in the Missouri Ozark Highlands, 2010-2012. 

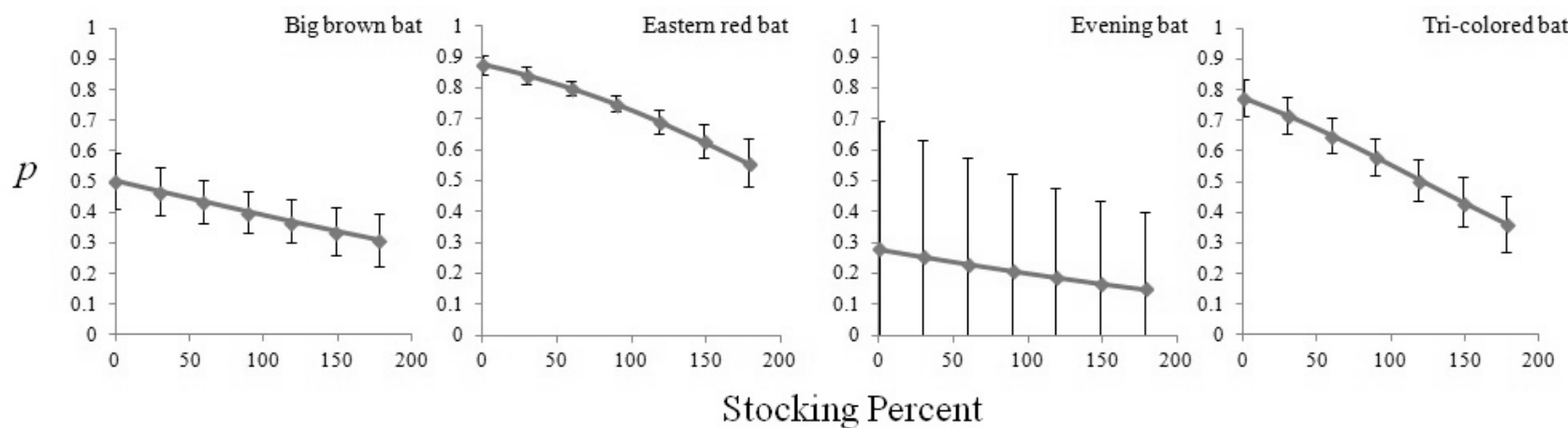

Stocking Percent

Figure 5. Probability of detection ( $p$ ) during acoustic surveys across the range of stand stocking (\%) for the big brown bat, eastern red bat, evening bat, and tri-colored bat in the Missouri Ozark Highlands, 2010-2012. 


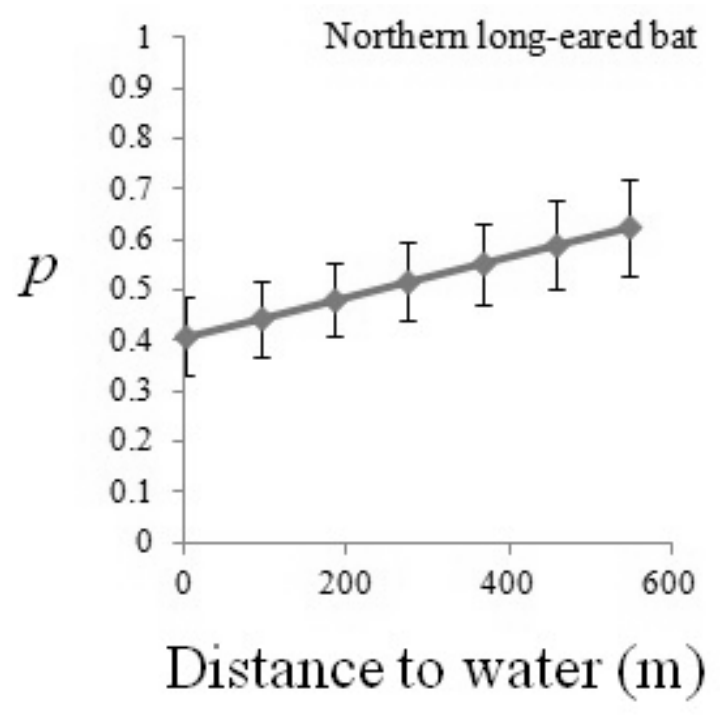

Figure 6. Probability of detection ( $p$ ) during acoustic surveys across the range of distance to water (m) for the northern long-eared bat in the Missouri Ozark Highlands, 2010-2012. 


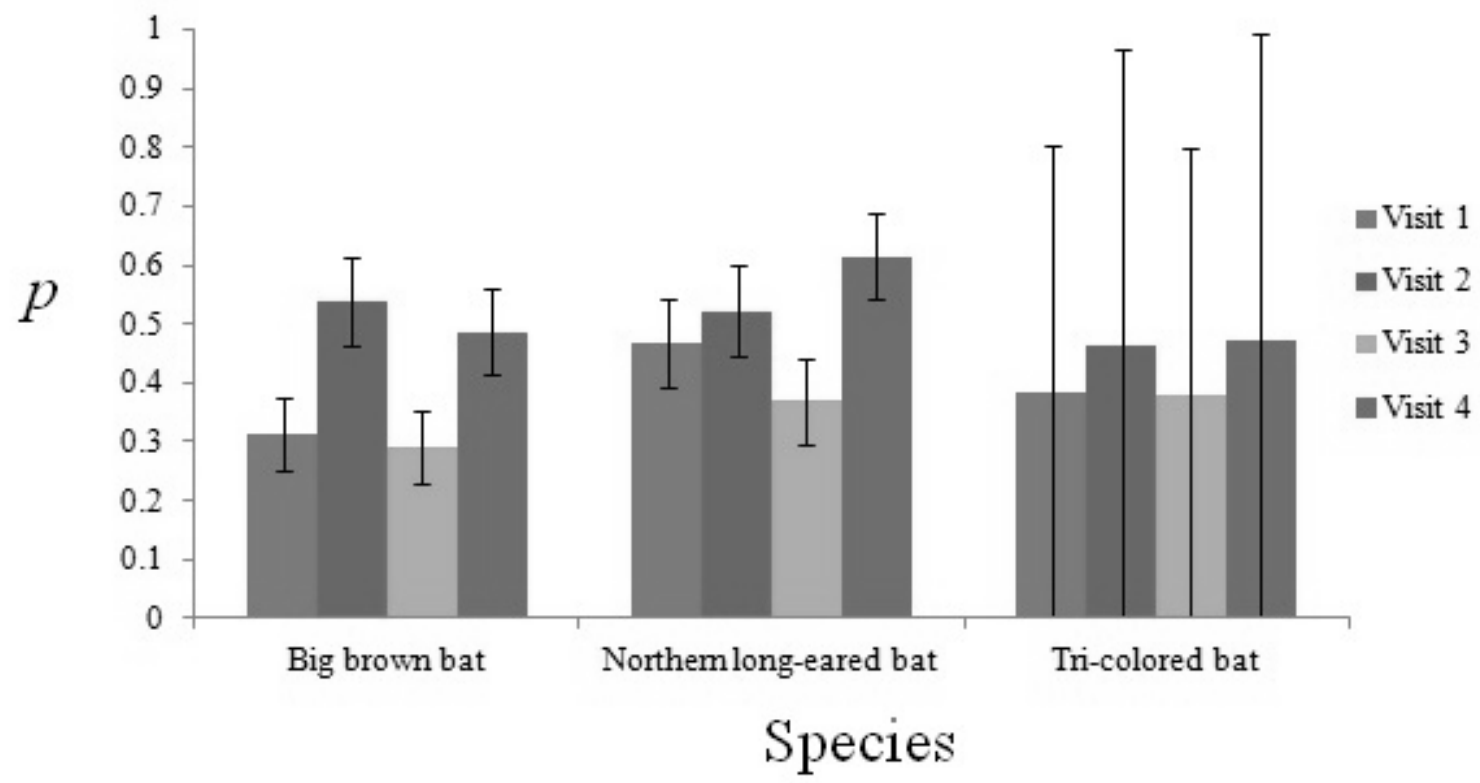

Figure 7. Probability of detection ( $p$ ) during acoustic surveys for 4 visits for the big brown bat, northern long-eared bat, and tri-colored bat in the Missouri Ozark Highlands, 2010-2012. 


\section{APPENDIX}

Appendix. Candidate site occupancy models evaluated to determine factors affecting probability of detection ( $p$ ) from acoustic surveys for 5 bat species in the Missouri Ozark Highlands, 2010-2012. We present number of parameters (k), log likelihood (LogLik), Akaike's Information Criterion (AIC), delta AIC ( $\triangle \mathrm{AIC}$ ), and AIC weight $\left(w_{i}\right)$ for each model.

\begin{tabular}{|c|c|c|c|c|c|}
\hline Model by species & $\mathrm{k}$ & LogLik & AIC & $\Delta \mathrm{AIC}$ & $w_{i}$ \\
\hline \multicolumn{6}{|l|}{ Big brown bat } \\
\hline$\Psi$ (habitat),p(v,weather,date,stocking) & 12 & 1532.03 & 1556.03 & 0 & 0.554 \\
\hline$\Psi$ (habitat),p(v,global) & 13 & 1530.92 & 1556.92 & 0.89 & 0.355 \\
\hline$\Psi$ (habitat),p(v,weather,date) & 11 & 1538.69 & 1560.69 & 4.66 & 0.0539 \\
\hline$\Psi$ (habitat),p(v,weather,date,water) & 12 & 1537.44 & 1561.44 & 5.41 & 0.037 \\
\hline$\Psi$ (habitat),p(weather,date,stocking) & 9 & 1557.3 & 1575.3 & 19.27 & 0 \\
\hline$\Psi$ (habitat),p(global) & 10 & 1555.73 & 1575.73 & 19.7 & 0 \\
\hline$\Psi$ (habitat), $p$ (weather,date) & 8 & 1565.58 & 1581.58 & 25.55 & ? \\
\hline$\Psi$ (habitat),p(weather,date,water) & 9 & 1563.75 & 1581.75 & 25.72 & 0 \\
\hline$\Psi$ (habitat), $p$ (v,date,water,stocking) & 10 & 1565.71 & 1585.71 & 29.68 & 0 \\
\hline$\Psi$ (habitat),p(v,date,stocking) & 9 & 1568.45 & 1586.45 & 30.42 & 0 \\
\hline$\Psi$ (habitat),p(v,water,date) & 9 & 1573.44 & 1591.44 & 35.41 & 0 \\
\hline$\Psi$ (habitat), $p$ (v,date) & 8 & 1576.39 & 1592.39 & 36.36 & 0 \\
\hline$\Psi$ (habitat),p(date,water,stocking) & 7 & 1581.48 & 1595.48 & 39.45 & 0 \\
\hline$\Psi($ habitat $), p$ (date,stocking) & 6 & 1584.21 & 1596.21 & 40.18 & 0 \\
\hline$\Psi$ (habitat), $p$ (water,date) & 6 & 1589.08 & 1601.08 & 45.05 & 0 \\
\hline$\Psi$ (habitat),p(date) & 5 & 1592.01 & 1602.01 & 45.98 & 0 \\
\hline$\Psi$ (habitat), $p$ (v,water,stocking) & 9 & 1613.53 & 1631.53 & 75.5 & 0 \\
\hline$\Psi$ (habitat),p(v,weather,water,stocking) & 12 & 1608.94 & 1632.94 & 76.91 & 0 \\
\hline$\Psi$ (habitat),p(v,stocking) & 8 & 1617.12 & 1633.12 & 77.09 & 0 \\
\hline$\Psi$ (habitat),p(v,weather,stocking) & 11 & 1611.48 & 1633.48 & 77.45 & 0 \\
\hline$\Psi$ (habitat), $p$ (v,water) & 8 & 1621.57 & 1637.57 & 81.54 & 0 \\
\hline$\Psi$ (habitat),p(weather,water,stocking) & 9 & 1619.83 & 1637.83 & 81.8 & 0 \\
\hline$\Psi$ (habitat),p(weather,stocking) & 8 & 1622.68 & 1638.68 & 82.65 & 0 \\
\hline$\Psi$ (habitat), $p$ (v,weather,water) & 11 & 1616.84 & 1638.84 & 82.81 & 0 \\
\hline$\Psi($ habitat $), p(\mathrm{v})$ & 7 & 1625.15 & 1639.15 & 83.12 & 0 \\
\hline$\Psi$ (habitat),p(v,weather) & 10 & 1619.34 & 1639.34 & 83.31 & 0 \\
\hline$\Psi$ (habitat),p(water,stocking) & 6 & 1628.04 & 1640.04 & 84.01 & 0 \\
\hline$\Psi$ (habitat), $p$ (stocking) & 5 & 1631.59 & 1641.59 & 85.56 & 0 \\
\hline$\Psi$ (habitat), $p$ (weather,water) & 8 & 1629.1 & 1645.1 & 89.07 & 0 \\
\hline
\end{tabular}




\begin{tabular}{|c|c|c|c|c|c|}
\hline Model by species & $\mathrm{k}$ & LogLik & AIC & $\triangle \mathrm{AIC}$ & $w_{i}$ \\
\hline$\Psi$ (habitat), $p$ (water) & 5 & 1635.95 & 1645.95 & 89.92 & 0 \\
\hline$\Psi$ (habitat),p(weather) & 7 & 1631.98 & 1645.98 & 89.95 & 0 \\
\hline$\Psi(),. p()$. & 2 & 1643.13 & 1647.13 & 91.1 & 0 \\
\hline$\Psi($ habitat $), p()$. & 4 & 1639.5 & 1647.5 & 91.47 & 0 \\
\hline \multicolumn{6}{|l|}{ Eastern red bat } \\
\hline$\Psi$ (habitat),p(weather,date,stocking) & 9 & 1493.93 & 1511.93 & 0 & 0.519 \\
\hline$\Psi$ (habitat),p(v,weather,date,stocking) & 12 & 1489.78 & 1513.78 & 1.85 & 0.2058 \\
\hline$\Psi($ habitat),p(global) & 10 & 1493.87 & 1513.87 & 1.94 & 0.1967 \\
\hline$\Psi$ (habitat),p(v,global) & 13 & 1489.71 & 1515.71 & 3.78 & 0.0784 \\
\hline$\Psi$ (habitat),p(date,stocking) & 6 & 1518.59 & 1530.59 & 18.66 & 0 \\
\hline$\Psi$ (habitat),p(weather,stocking) & 8 & 1516.38 & 1532.38 & 20.45 & 0 \\
\hline$\Psi$ (habitat),p(date,water,stocking) & 7 & 1518.48 & 1532.48 & 20.55 & 0 \\
\hline$\Psi$ (habitat),p(v,date,stocking) & 9 & 1516.09 & 1534.09 & 22.16 & 0 \\
\hline$\Psi$ (habitat),p(weather,water,stocking) & 9 & 1516.23 & 1534.23 & 22.3 & 0 \\
\hline$\Psi$ (habitat),p(v,weather,stocking) & 11 & 1512.58 & 1534.58 & 22.65 & 0 \\
\hline$\Psi$ (habitat),p(v,date, water,stocking) & 10 & 1515.97 & 1535.97 & 24.04 & 0 \\
\hline$\Psi$ (habitat),p(v,weather, water,stocking) & 12 & 1512.42 & 1536.42 & 24.49 & 0 \\
\hline$\Psi$ (habitat),p(weather,date) & 8 & 1524.31 & 1540.31 & 28.38 & 0 \\
\hline$\Psi$ (habitat),p(stocking) & 5 & 1531.66 & 1541.66 & 29.73 & 0 \\
\hline$\Psi$ (habitat),p(weather,date,water) & 9 & 1524.05 & 1542.05 & 30.12 & 0 \\
\hline$\Psi$ (habitat),p(v,weather,date) & 11 & 1520.49 & 1542.49 & 30.56 & 0 \\
\hline$\Psi$ (habitat),p(water,stocking) & 6 & 1531.5 & 1543.5 & 31.57 & 0 \\
\hline$\Psi$ (habitat),p(v,weather, date, water) & 12 & 1520.23 & 1544.23 & 32.3 & 0 \\
\hline$\Psi$ (habitat),p(v,stocking) & 8 & 1528.98 & 1544.98 & 33.05 & 0 \\
\hline$\Psi$ (habitat),p(v,water,stocking) & 9 & 1528.81 & 1546.81 & 34.88 & 0 \\
\hline$\Psi$ (habitat),p(date) & 5 & 1546.96 & 1556.96 & 45.03 & 0 \\
\hline$\Psi$ (habitat),p(water,date) & 6 & 1546.61 & 1558.61 & 46.68 & 0 \\
\hline$\Psi$ (habitat),p(weather) & 7 & 1545 & 1559 & 47.07 & 0 \\
\hline$\Psi$ (habitat),p(v,date) & 8 & 1544.47 & 1560.47 & 48.54 & 0 \\
\hline$\Psi$ (habitat), $p$ (weather,water) & 8 & 1544.69 & 1560.69 & 48.76 & 0 \\
\hline$\Psi$ (habitat),p(v,weather) & 10 & 1541.52 & 1561.52 & 49.59 & 0 \\
\hline$\Psi$ (habitat),p(v,water,date) & 9 & 1544.12 & 1562.12 & 50.19 & 0 \\
\hline$\Psi$ (habitat),p(v,weather, water) & 11 & 1541.19 & 1563.19 & 51.26 & 0 \\
\hline$\Psi($ habitat $), p()$. & 4 & 1558.88 & 1566.88 & 54.95 & 0 \\
\hline$\Psi$ (habitat), $p$ (water) & 5 & 1558.56 & 1568.56 & 56.63 & 0 \\
\hline$\Psi($ habitat $), p(\mathrm{v})$ & 7 & 1556.23 & 1570.23 & 58.3 & 0 \\
\hline$\Psi$ (habitat),p(v,water) & 8 & 1555.9 & 1571.9 & 59.97 & 0 \\
\hline$\Psi(),. \mathrm{p}()$. & 2 & 1571.07 & 1575.07 & 63.14 & 0 \\
\hline
\end{tabular}




\begin{tabular}{|c|c|c|c|c|c|}
\hline Model by species & $\mathrm{k}$ & LogLik & AIC & $\triangle \mathrm{AIC}$ & $w_{i}$ \\
\hline \multicolumn{6}{|l|}{ Northern long-eared bat } \\
\hline$\Psi$ (habitat),p(v,weather,water) & 11 & 1523.6 & 1545.6 & 0 & 0.4592 \\
\hline$\Psi$ (habitat),p(v,weather,date,water) & 12 & 1522.86 & 1546.86 & 1.26 & 0.2446 \\
\hline$\Psi$ (habitat),p(v,weather,water,stocking) & 12 & 1523.59 & 1547.59 & 1.99 & 0.1698 \\
\hline$\Psi$ (habitat),p(v,global) & 13 & 1522.75 & 1548.75 & 3.15 & 0.0951 \\
\hline$\Psi$ (habitat), $p$ (v,weather) & 10 & 1532.71 & 1552.71 & 7.11 & 0.0131 \\
\hline$\Psi$ (habitat),p(v,weather,date) & 11 & 1531.82 & 1553.82 & 8.22 & 0.0075 \\
\hline$\Psi($ habitat $), p(v, w e a t h e r$, stocking) & 11 & 1532.66 & 1554.66 & 9.06 & 0.005 \\
\hline$\Psi$ (habitat),p(v,weather,date,stocking) & 12 & 1531.62 & 1555.62 & 10.02 & 0.0031 \\
\hline$\Psi$ (habitat),p(weather,water) & 8 & 1542.12 & 1558.12 & 12.52 & 0.0009 \\
\hline$\Psi$ (habitat),p(v,water,date) & 9 & 1541.9 & 1559.9 & 14.3 & 0.0004 \\
\hline$\Psi($ habitat $), p(v$, water $)$ & 8 & 1544.06 & 1560.06 & 14.46 & 0.0003 \\
\hline$\Psi$ (habitat),p(weather,date,water) & 9 & 1542.09 & 1560.09 & 14.49 & 0.0003 \\
\hline$\Psi$ (habitat),p(weather,water,stocking) & 9 & 1542.09 & 1560.09 & 14.49 & 0.0003 \\
\hline$\Psi$ (habitat),p(v,date, water,stocking) & 10 & 1541.9 & 1561.9 & 16.3 & 0.0001 \\
\hline$\Psi$ (habitat),p(v,water,stocking) & 9 & 1543.99 & 1561.99 & 16.39 & 0.0001 \\
\hline$\Psi($ habitat),p(global) & 10 & 1542.07 & 1562.07 & 16.47 & 0.0001 \\
\hline$\Psi$ (habitat),p(weather) & 7 & 1551.31 & 1565.31 & 19.71 & 0 \\
\hline$\Psi$ (habitat),p(v,date) & 8 & 1550.85 & 1566.85 & 21.25 & 0 \\
\hline$\Psi$ (habitat),p(weather,date) & 8 & 1551.25 & 1567.25 & 21.65 & 0 \\
\hline$\Psi$ (habitat),p(weather,stocking) & 8 & 1551.3 & 1567.3 & 21.7 & 0 \\
\hline$\Psi($ habitat $), p(\mathrm{v})$ & 7 & 1553.33 & 1567.33 & 21.73 & 0 \\
\hline$\Psi$ (habitat),p(water,date) & 6 & 1556.43 & 1568.43 & 22.83 & 0 \\
\hline$\Psi$ (habitat),p(water) & 5 & 1558.49 & 1568.49 & 22.89 & 0 \\
\hline$\Psi($ habitat $), p(\mathrm{v}$, date,stocking) & 9 & 1550.84 & 1568.84 & 23.24 & 0 \\
\hline$\Psi$ (habitat),p(weather,date,stocking) & 9 & 1551.25 & 1569.25 & 23.65 & 0 \\
\hline$\Psi($ habitat),p(v,stocking) & 8 & 1553.3 & 1569.3 & 23.7 & 0 \\
\hline$\Psi$ (habitat),p(water,stocking) & 6 & 1558.42 & 1570.42 & 24.82 & 0 \\
\hline$\Psi$ (habitat),p(date,water,stocking) & 7 & 1556.43 & 1570.43 & 24.83 & 0 \\
\hline$\Psi$ (habitat),p(date) & 5 & 1565.32 & 1575.32 & 29.72 & 0 \\
\hline$\Psi($ habitat $), p()$. & 4 & 1567.7 & 1575.7 & 30.1 & 0 \\
\hline$\Psi$ (habitat),p(date,stocking) & 6 & 1565.3 & 1577.3 & 31.7 & 0 \\
\hline$\Psi$ (habitat),p(stocking) & 5 & 1567.67 & 1577.67 & 32.07 & 0 \\
\hline$\Psi(),. p()$. & 2 & 1574.72 & 1578.72 & 33.12 & 0 \\
\hline \multicolumn{6}{|l|}{ Evening bat } \\
\hline$\Psi$ (habitat),p(date,stocking) & 6 & 793.28 & 805.28 & 0 & 0.2709 \\
\hline$\Psi$ (habitat),p(date) & 5 & 795.68 & 805.68 & 0.4 & 0.2218 \\
\hline$\Psi$ (habitat),p(stocking) & 5 & 797.16 & 807.16 & 1.88 & 0.1058 \\
\hline
\end{tabular}




\begin{tabular}{|c|c|c|c|c|c|}
\hline Model by species & $\mathrm{k}$ & LogLik & AIC & $\triangle \mathrm{AIC}$ & $w_{i}$ \\
\hline$\Psi$ (habitat),p(date, water,stocking) & 7 & 793.27 & 807.27 & 1.99 & 0.1002 \\
\hline$\Psi$ (habitat),p(water,date) & 6 & 795.49 & 807.49 & 2.21 & 0.0897 \\
\hline$\Psi($ habitat $), p()$. & 4 & 799.89 & 807.89 & 2.61 & 0.0735 \\
\hline$\Psi$ (habitat),p(water,stocking) & 6 & 797 & 809 & 3.72 & 0.0422 \\
\hline$\Psi$ (habitat), $p$ (water) & 5 & 799.89 & 809.89 & 4.61 & 0.027 \\
\hline$\Psi($ habitat $), p(\mathrm{v}, \mathrm{date}, \mathrm{stocking})$ & 9 & 792.48 & 810.48 & 5.2 & 0.0201 \\
\hline$\Psi($ habitat $), p(\mathrm{v}$, date $)$ & 8 & 794.87 & 810.87 & 5.59 & 0.0166 \\
\hline$\Psi$ (habitat),p(v,stocking) & 8 & 796.43 & 812.43 & 7.15 & 0.0076 \\
\hline$\Psi$ (habitat),p(v,date,water,stocking) & 10 & 792.46 & 812.46 & 7.18 & 0.0075 \\
\hline$\Psi($ habitat $), p(\mathrm{v}$, water,date $)$ & 9 & 794.66 & 812.66 & 7.38 & 0.0068 \\
\hline$\Psi($ habitat $), p(\mathrm{v})$ & 7 & 799.15 & 813.15 & 7.87 & 0.0053 \\
\hline$\Psi$ (habitat),p(v,water,stocking) & 9 & 796.27 & 814.27 & 8.99 & 0.003 \\
\hline$\Psi($ habitat $), p(\mathrm{v}$, water $)$ & 8 & 799.14 & 815.14 & 9.86 & 0.002 \\
\hline$\Psi(),. p()$. & 2 & 816.71 & 820.71 & 15.43 & 0.0001 \\
\hline \multicolumn{6}{|l|}{ Tri-colored bat } \\
\hline$\Psi$ (habitat),p(v,weather,stocking) & 11 & 1648.12 & 1670.12 & 0 & 0.2818 \\
\hline$\Psi$ (habitat),p(v,weather,date,stocking) & 12 & 1646.79 & 1670.79 & 0.67 & 0.2016 \\
\hline$\Psi$ (habitat),p(weather,stocking) & 8 & 1656.05 & 1672.05 & 1.93 & 0.1074 \\
\hline$\Psi$ (habitat),p(v,weather,water,stocking) & 12 & 1648.12 & 1672.12 & 2 & 0.1037 \\
\hline$\Psi($ habitat $), p(\mathrm{v}$, global $)$ & 13 & 1646.78 & 1672.78 & 2.66 & 0.0745 \\
\hline$\Psi$ (habitat),p(stocking) & 5 & 1663.6 & 1673.6 & 3.48 & 0.0495 \\
\hline$\Psi$ (habitat),p(weather,date,stocking) & 9 & 1655.67 & 1673.67 & 3.55 & 0.0478 \\
\hline$\Psi$ (habitat),p(weather,water,stocking) & 9 & 1656.01 & 1674.01 & 3.89 & 0.0403 \\
\hline$\Psi$ (habitat),p(date,stocking) & 6 & 1663.4 & 1675.4 & 5.28 & 0.0201 \\
\hline$\Psi$ (habitat),p(water,stocking) & 6 & 1663.59 & 1675.59 & 5.47 & 0.0183 \\
\hline$\Psi($ habitat),p(global) & 10 & 1655.61 & 1675.61 & 5.49 & 0.0181 \\
\hline$\Psi($ habitat $), p(\mathrm{v}$, stocking $)$ & 8 & 1659.93 & 1675.93 & 5.81 & 0.0154 \\
\hline$\Psi($ habitat),p(date,water,stocking) & 7 & 1663.4 & 1677.4 & 7.28 & 0.0074 \\
\hline$\Psi($ habitat $), p(\mathrm{v}$, date,stocking) & 9 & 1659.78 & 1677.78 & 7.66 & 0.0061 \\
\hline$\Psi($ habitat $), p(\mathrm{v}$, water,stocking) & 9 & 1659.93 & 1677.93 & 7.81 & 0.0057 \\
\hline$\Psi$ (habitat),p(v,date,water,stocking) & 10 & 1659.77 & 1679.77 & 9.65 & 0.0023 \\
\hline$\Psi$ (habitat),p(v,weather) & 10 & 1677.95 & 1697.95 & 27.83 & 0 \\
\hline$\Psi$ (habitat),p(v,weather,date) & 11 & 1676.23 & 1698.23 & 28.11 & 0 \\
\hline$\Psi$ (habitat),p(v,weather,water) & 11 & 1677.76 & 1699.76 & 29.64 & 0 \\
\hline$\Psi$ (habitat),p(weather) & 7 & 1685.82 & 1699.82 & 29.7 & 0 \\
\hline$\Psi$ (habitat),p(v,weather,date, water) & 12 & 1675.94 & 1699.94 & 29.82 & 0 \\
\hline$\Psi($ habitat $), p()$. & 4 & 1692.17 & 1700.17 & 30.05 & 0 \\
\hline$\Psi$ (habitat),p(weather,date) & 8 & 1685.23 & 1701.23 & 31.11 & 0 \\
\hline
\end{tabular}




\begin{tabular}{lrrrrr}
\hline Model by species & $\mathrm{k}$ & LogLik & AIC & $\Delta$ AIC & $w_{i}$ \\
\hline$\Psi$ (habitat), $p$ (weather,water) & 8 & 1685.47 & 1701.47 & 31.35 & 0 \\
$\Psi$ (habitat), $p$ (water) & 5 & 1691.93 & 1701.93 & 31.81 & 0 \\
$\Psi$ (habitat), $p$ (date) & 5 & 1692.13 & 1702.13 & 32.01 & 0 \\
$\Psi$ (habitat), $p$ (v) & 7 & 1688.56 & 1702.56 & 32.44 & 0 \\
$\Psi$ (habitat),p(weather,date,water) & 9 & 1684.78 & 1702.78 & 32.66 & 0 \\
$\Psi$ (habitat), $p$ (water,date) & 6 & 1691.9 & 1703.9 & 33.78 & 0 \\
$\Psi$ (habitat), $p$ (v,water) & 8 & 1688.32 & 1704.32 & 34.2 & 0 \\
$\Psi$ (habitat), $p$ (v,date) & 8 & 1688.54 & 1704.54 & 34.42 & 0 \\
$\Psi$ (habitat), $p$ (v,water,date) & 9 & 1688.31 & 1706.31 & 36.19 & 0 \\
$\Psi(),. p()$. & 2 & 1708.46 & 1712.46 & 42.34 & 0 \\
\hline
\end{tabular}


CHAPTER 2

\section{BAT OCCUPANCY OF FORESTS AND MANAGED SAVANNA AND WOODLAND IN THE MISSOURI OZARK REGION}

\section{ABSTRACT}

Many Missouri land management agencies are restoring savannas and woodlands using prescribed fire and forest thinning, and information is needed on how wildlife species respond to these management activities. Our objectives were to determine how site occupancy by bats varies among savannas, woodlands, and forests as a function of vegetation structure, landscape pattern, and management history. We identified sites that were actively managed for savanna and woodland conditions, and control areas on similar landforms that had no recent management and had succeeded to closed-canopy forest. We used Anabat detectors to survey bats during August 2010, May to July of 2011, and May to June of 2012 and single-species site occupancy models to estimate detection probability and site occupancy. We evaluated a priori hypotheses in an information theoretic approach by evaluating support for candidate models that included habitat, landscape, and management effects. The probability of detecting bat species with acoustic detectors varied by species and was related to temperature, relative humidity, barometric pressure, tree density, Julian date, distance to water, and visit. The probability a site was occupied by foraging bats varied among species as a function of percent forest 
and urban land cover, stand stocking, distance to water and roads, number of fires in the last 10 years, and vegetative composition. Habitat conditions created by savanna and woodland restoration and management resulted in greater occupancy of the big brown bat, eastern red bat, evening bat, and tri-colored bat than was observed in mature, nonmanaged forest. The northern long-eared bat, however, had greater occupancy in highly forested landscapes and closed canopy forest or woodlands with open understories.

\section{INTRODUCTION}

Many bat populations are declining due to habitat degradation or destruction, urbanization, and deforestation (Fenton, 1997). Recently, white-nose syndrome and fatalities at windfarms have caused several bat populations to decline very quickly (Blehert et al., 2009; Ellison, 2012). Even small colonies of bats can eat millions of insects yearly, and the loss of these populations could have far-reaching impacts due to loss of the ecosystem services they provide (Boyles et al., 2011).

Many bats roost and forage in forests. Land management agencies in the Midwestern United States are restoring many forested areas to their historic structure and composition as savannas and woodlands using prescribed fire and thinning. Oak savannas and woodlands have declined from approximately 13 million hectares (ha) in the Midwest since European settlement (Abrams, 1992). Historically, fires started by lightning and Native Americans maintained savanna and woodland ecosystems. After Europeans settled in the Midwest, savannas and woodlands decreased due to conversion to settlements or farmland and succession to forest as a result of fire control (Abrams, 1992). The goal of land management agencies is to restore savanna and woodland 
communities by reducing the understory and midstory woody canopy, and to a lesser extent the overstory canopy, to allow increased sunlight to reach the ground by using fire (McCarty, 2002; Nelson, 2002). Long-term repeated fire reduces the density of understory and midstory shrubs and trees and results in greater abundance of grasses and forbs while retaining an overstory of mature trees. Occasional periods without fire allows some fire adapted trees (i.e. oaks and pine) to be recruited to the overstory. It is important to know how savanna and woodland restoration and prescribed fire affect bats because of the extent of these activities and concern for bat populations.

Little is known about foraging behaviors by different species of bats, but foraging strategies and use of savanna, woodland, and forest likely varies among species due to differences in wing morphology. The aspect ratio of the wing is the length of the wingspan squared divided by the surface area of the wing, and the wing loading is mass of the bat divided by total wing area. These adaptations help determine whether a species is adapted for cluttered (such as dense forest) or open (such as savanna) habitat. Bigger bat species with high wing loading and high aspect ratio use forests that have been managed by either fire and thinning, whereas smaller bats with low wing loading and low aspect ratio are usually not affected as much by tree density (Armitage and Ober, 2012; Elmore et al., 2005; Loeb and O'Keefe, 2006; Loeb and Waldrop, 2008; Patriquin and Barclay, 2003).

In addition to the vegetation structure within patches, landscape composition and structure can affect bat habitat use. The amount and distribution of urban and agricultural areas interact with the composition and distribution of forests. Some bats fly long 
distances each night from roosts to foraging sites, so landscape scale factors may affect these species either positively or negatively (Gorresen and Willig, 2004; Yates and Muzika, 2006).

Bats are volant, nocturnal mammals, which poses challenges to their study including difficulty in trapping and counting. Counting individuals and trapping them are both labor intensive and biased towards species or individuals that do not detect the traps or nets (Berry et al., 2004; Larsen et al., 2007). Echolocation detectors allow researchers to sample more sites than trapping and determine the presence of bat species in an area. However, environmental conditions and characteristics of the bat echolocation call influence how far the call can be detected (Lacki et al., 2007). Because the probability of detecting bats with acoustic detectors varies by these factors, use of analysis methods that account for detection probability $<1$ are required.

Several studies have used estimation of occupancy to determine habitats used by bats (Gorresen et al., 2008; Hein et al., 2009; Roberts et al., 2011; Yates and Muzika, 2006). Site occupancy $(\Psi)$ is the probability that a site or sampling unit is occupied by a species and occupancy modeling incorporates an estimate of the probability of detection (p) to account for the fact that $p$ is usually $<1$ (Mackenzie et al., 2006). Occupancy modeling requires that sites are surveyed during multiple visits over a short time period, during which the population is assumed closed to emigration and immigration to create a detection history. The detection history and values of site and sampling covariates are used to estimate $p$ and $\Psi$ simultaneously (Mackenzie et al., 2006). 
Our objective was to determine the effects of savanna and woodland restoration on $\Psi$ of big brown bats (Eptesicus fuscus), northern long-eared bats (Myotis septentrionalis), evening bats (Nycticeius humeralis), tri-colored bats (Perimyotis subflavus), and eastern red bats (Lasiurus borealis). Specifically, we evaluated 1) the relationship between vegetative structure and $\Psi$ across a gradient of managed savanna and woodland, and forest with no recent management and 2) the relationship between landscape composition and structure and $\Psi$. We hypothesized that $\Psi$ would vary by species due to differences in wing morphology and echolocation characteristics and be affected by tree density, distance to water, distance to roads, vegetative composition, forest aggregation, road density, and percent forest and urban land cover. Overall, we hypothesized that vegetative structural conditions created by savanna and woodland restoration and management would result in greater $\Psi$ for the big brown bat, eastern red bat, evening bat, and tri-colored bat than in mature, un-managed forest; and that these conditions would have less of an effect on $\Psi$ of northern long-eared bats.

\section{STUDY AREA}

We conducted our study in the Ozark Highlands of southern Missouri. The Ozark Highlands are characterized by carbonate bedrock with many karst features and consists of plains, gently rolling hills and rugged uplands with elevations of 2,500 ft (Ethridge, 2009; Nigh and Schroeder, 2002). Soils are typically rocky and historically supported oak and oak-pine savannas, woodlands, and forests. Most streams in the area are springfed and clear. Common trees in upland forest were black oak (Quercus velutina), scarlet oak (Q. coccinea), white oak (Q. alba), post oak (Q. stellata), blackjack oak (Q. 
marilandica), black hickory (Carya texana), and shortleaf pine (Pinus echinata). White oak, red oak (Q. rubra), bitternut hickory (C. cordiformis), and flowering dogwood (Cornus florida) were more prevalent on mesic slopes. River birch (Betula nigra), silver maple (Acer saccharinum), eastern cottonwood (Populus deltoides), American sycamore (Platanus occidentalis), black willow (Salix nigra), and box elder (A. negundo) were common in riparian areas. Openlands consisted of bluestem (Andropogon gerardii, Schizachyrium scoparium) prairies, eastern red cedar (Juniperus virginiana) glades (McNab and Avers, 1994), and improved cool-season (Festuca spp.) pasturelands.

\section{METHODS}

\section{Locations of Sites and Survey Points}

We consulted with land managers from Missouri Department of Conservation (MDC), Department of Natural Resources (DNR), The Nature Conservancy (TNC), and Mark Twain National Forest (MTNF) to select study areas that included sites with a history of management (predominantly prescribed fire and thinning) to restore savannas or woodlands and that had achieved or demonstrated substantial progress toward the desired structure and composition.

We identified sites actively managed for savanna and woodland conditions and control sites with no recent management at each study area. Most sites were part of a larger study on the effects of savanna and woodland restoration on birds, bats, and vegetation. We used point transects from bird surveys to locate bat survey points. Transects were initially established by randomly placing a $250 \mathrm{~m}$ grid over a site and 
mapping a transect of 10-20 points spaced $250 \mathrm{~m}$ apart and at least $50 \mathrm{~m}$ from the edge of the managed site. We selected every $2^{\text {nd }}$ or $3^{\text {rd }}$ point along the bird transects for the bat surveys to get $\leq 6$ points per transect. Additional points were located consistent with an earlier bat study (Amelon, 2007) by randomly locating points using a GIS in managed savanna and woodland sites, and non-managed forests such that points were $>250 \mathrm{~m}$ apart.

\section{Acoustic Detection}

We surveyed bats with either Anabat II bat detectors and Zero-Crossing Analysis Interference Modules with Compact Flash memory storage (CF ZCAIM) or Anabat SD1 (combined detector and storage model; Titley Electronics, Columbia, Missouri). The detector and a 12-volt battery were housed in a waterproof Pelican case with the microphone pointed through a hole with a 45 degree PVC elbow attached to the side of the case to protect the microphone and direct the detection cone upward. Anabat detectors weatherproofed in this way record similar numbers of calls as other techniques

including no weatherproofing (Britzke et al., 2010). We calibrated the sensitivity of each Anabat detector to standardize the detection distance and area sampled as described by Livengood (2003).

We placed a detector at each point for two consecutive nights. We programmed the detectors to start recording at 1800 and stop at 0600 . We placed the detector on the ground with the microphone oriented upward and toward the most open area in the vegetation to exclude as much insect noise as possible. We picked up the detectors after 
two nights and downloaded data from the compact flash (CF) card to a computer. We analyzed and identified the calls with AnalookW (Corben, 2007). We used digital filters to eliminate ambient noise, low quality sequences, and sequences with less than 5 call pulses (Amelon, 2007). We compared the collected calls to a library of known calls and published information on quantitative call characteristics to identify calls to species. Minimum frequency, duration, characteristic frequency, initial slope, characteristic slope, cadence, and consistency of calls were the quantitative call characteristics that were used to distinguish between species. Each night was divided into two sampling periods (18000000 and 0000-0600), and the two sampling periods in each of two consecutive nights were treated as 4 visits for occupancy modeling. We constructed a detection history for each point by assigning 1 to a visit when a species was detected and a 0 if it was not detected.

\section{Vegetation and Landscape Measurements}

We measured diameter at breast height (DBH) of trees selected with a 10-factor prism at survey points with a DBH tape and recorded trees with a DBH $>2.5$ centimeters (cm). We used prism plot data to calculate percent stocking of all trees and also stem densities of saplings (2.5-12.5 cm DBH), poletimber (12.5-27.5 cm DBH), and sawlogs (> $27.5 \mathrm{~cm} \mathrm{DBH)}$ at each point (Gingrich, 1967). We classified points with $>80 \%$ stand stocking as forest and $0 \%$ to $80 \%$ stand stocking as savanna/woodland to describe vegetation type. We calculated small stems/ha by counting the trees with a $\mathrm{DBH}<2.5$ $\mathrm{cm}$ and greater than 0.5 meters tall in a 5 meter radius around the point. We classified 
trees in each plot as either conifer or hardwood, and we used this classification with the DBH measurements to calculate conifer basal area (BA).

We measured the percent of the landscape in forest, open, and urban land cover and a forest aggregation index within a $2 \mathrm{~km}$ and $16 \mathrm{~km}$ buffer (Amelon, 2007) around each survey point. We used ArcMap (ESRI, version 9.3.1, ESRI, Redlands, California) to condense the land classifications from the National Land Cover Database (Fry et al., 2006) to forest, open, and urban land cover. We used FRAGSTATS 3.3 (McGarigal and Marks, 1994) to calculate percent area in forest, open, and urban land cover, and forest aggregation. Forest aggregation is an index of how patchy the forest is: high values indicate few large patches and low values indicated many small patches.

We calculated road density (m/ha) within a $2 \mathrm{~km}$ buffer and a $16 \mathrm{~km}$ buffer and distance to nearest road or trail (m) using a statewide layer of transportation data for Missouri (MSIDS 2011) and Arkansas (GeoStor 2009). We used a statewide layer of hydrography for Missouri (National Hydrography Dataset Plus, U.S. Environmental Protection Agency and U.S. Geological Survey, 2005) to calculate distance to nearest water $(\mathrm{m})$.

We compiled weather data from the National Climatic Data Center (NCDC 2011) for the stations closest to each site: Rolla, Kaiser Lake Ozark, Farmington, Cape Girardeau, West Plains, Springfield, Whiteman Air Force Base, Spirit of St. Louis Airport, and Poplar Bluff. We calculated maximum dry bulb temperature $\left({ }^{\circ} \mathrm{C}\right)$, 
maximum relative humidity (\%), and mean barometric pressure (in. Hg) from hourly values for the four survey visits.

\section{Data Analysis}

We fitted single-season occupancy models (Royle and Nichols, 2003) for each species with the program PRESENCE 5.3. We evaluated a priori hypotheses using an objective model selection criterion (Akaike's Information Criteria, AIC) to select the model that best explained the empirical data. We used a two-stage approach and first determined the best model for $p$ and then included the covariates from the best model for $p$ while evaluating covariates for $\Psi$. We considered visit, weather (temperature, relative humidity, and barometric pressure), Julian date, distance to nearest water source, and percent stand stocking as covariates for $p$ individually and in additive combinations. We considered conifer basal area, percent stand stocking, number of fires in the last 10 years, stems (saplings/acre, poletimber/acre, sawlogs/acre, small stems/hectare), distance to nearest water source, distance to nearest road, land cover in $2 \mathrm{~km}$ radius (percent area in forest and urban), land cover in $16 \mathrm{~km}$ radius (percent area in forest and urban), forest aggregation (2 km and $16 \mathrm{~km}$ radius), and road density (2 km and $16 \mathrm{~km}$ radius) as covariates for $\Psi$.

We evaluated all continuous covariates for $\Psi$ for multicolinearity by calculating tolerance values. We determined tolerance values were too low $(<0.4)$ when road density and percent urban, and forest aggregation and percent forest, were included in the same model, so we dropped road density and forest aggregation from the candidate 
models. We built the set of candidate models for each species first considering a null model and models with single covariates. We then considered models with additive combinations of covariates that when considered individually had AIC values less than the null model (Appendix). However, we only considered stem densities by tree size class or stand stocking, depending on which had the most support since they both represented different measures of tree density. The global model included all covariates except for the percent urban and percent forest at a $2 \mathrm{~km}$ scale. Some models would not converge for eastern red bat and big brown bat so we standardized covariate values for these species, which eliminated the problem.

We identified a confidence set of models with $\Delta \mathrm{AIC}<4$ and that did include uninformative parameters where the addition of a parameter did not overcome the 2 AIC point penalty for the parameter (Arnold, 2010; Burnham and Anderson, 2002). We model averaged the models in the confidence set to obtain the average coefficient, unconditional standard error, odds ratio, and 95\% confidence interval for the odds ratio for each covariate (Burnham and Anderson, 2002). We demonstrated effects of covariates by plotting model averaged predictions of $\Psi$ across the range of covariates represented by 7 points evenly spaced from $1^{\text {st }}$ to $99^{\text {th }}$ percentile, while holding other covariates at their mean.

\section{RESULTS}

We surveyed 369 points at 26 sites, however, detectors failed at 27 points resulting in a total of 342 points with data (Table 1). Two-hundred points were classed as 
forest ( $>80 \%$ stocking), and 142 points were classes as savanna/woodland $(<80 \%$ stocking). Stand stocking ranged from 0\%-178\% (Table 2). There were 565,624 call files across all years and sites, and we detected all 5 focal species.

\section{Big brown bat}

Big brown bats were detected at $65 \%$ of points for at least one visit. The most supported covariates for estimating $p$ were visit, temperature, relative humidity, barometric pressure, Julian date, and stocking (Table 3). There were 4 models for estimating $\Psi$ in the confidence set. The most supported model included stems and conifer basal area (Table 4) however confidence intervals for these covariates included 0 (Table 5). While their coefficients’ confidence intervals overlapped 0; saplings/acre, sawlogs/acre, small stems/hectare, and conifer BA had positive effects on $\Psi$ (Figure 3, 5, 6, 7), and poletimber/acre had a negative effect on $\Psi$ (Figure 4).

\section{Eastern red bat}

Eastern red bats were detected at $91 \%$ of points for at least one visit. The most supported covariates for estimating $p$ were temperature, relative humidity, barometric pressure, Julian date, and stand stocking (Table 3). There were 3 models for estimating $\Psi$ in the confidence set; the most supported model included $16 \mathrm{~km}$ land cover, stems, distance to road, and distance to water (Table 4). Small stems/ha and distance to road had coefficient confidence intervals that did not include 0 ; $\Psi$ increased from 0.88 - 1 from 0 - 66,818 stems/ha, and $\Psi$ decreased from $0.99-0.88$ from 2 - 1993 meters from a road (Table 5; Figure 6, 8). Percent forest in $16 \mathrm{~km}$, percent urban in $16 \mathrm{~km}$, and distance 
to water had positive effects on $\Psi$ (Figure 1, 2, 11), and saplings/acre, poletimber/acre, and sawlogs/acre had negative effects on $\Psi$ (Figure 3, 4, 5); however, confidence intervals for these effects overlapped 0 .

\section{Northern long-eared bat}

Northern long-eared bats were detected at $61 \%$ of points for at least one visit. The most supported covariates for estimating $p$ were visit, temperature, relative humidity, barometric pressure, and distance to water (Table 3). There were 2 models for estimating $\Psi$ in the confidence set; the most supported model included stems and $16 \mathrm{~km}$ land cover (Table 4). Percent forest in $16 \mathrm{~km}$ and percent urban in $16 \mathrm{~km}$ were the only covariates to have coefficient confidence intervals that did not include 0 ; $\Psi$ increased from 0.39 0.79 from $24-92 \%$ forest cover, and $\Psi$ decreased from $0.81-0.33$ from $2-12 \%$ urban cover (Table 5; Figure 1, 2). Saplings/acre, sawlogs/acre, small stems/hectare, conifer BA, and distance to water had negative effects on $\Psi$ (Figure 3, 5, 6, 7, 11), and poletimber/acre, distance to roads, tree stocking, and number of fires in the last 10 years had positive effects on $\Psi$ (Figure 4, 8, 9, 10); however, their coefficients' confidence intervals overlapped 0 .

\section{Evening bat}

Evening bats were detected at $24 \%$ of points for at least one visit. The most supported covariates for estimating $p$ were Julian date and stand stocking (Table 3). There was 1 model for estimating $\Psi$ in the confidence set and it included $16 \mathrm{~km}$ land cover, stocking, and fire (Table 4). Percent forest in $16 \mathrm{~km}$, percent urban in $16 \mathrm{~km}$, tree 
stocking, and the number of fires in the last 10 years had coefficient confidence intervals that did not include 0; $\Psi$ decreased from $0.60-0.14$ from $24-92 \%$ forest cover, $\Psi$ decreased from $0.40-0.07$ from $2-12 \%$ urban cover, $\Psi$ decreased from $0.59-0.06$ from $0-178 \%$ stand stocking, and $\Psi$ increased from $0.17-0.63$ from $0-8$ years since the last fire (Table 5; Figure 1, 2, 9, 10).

\section{Tri-colored bat}

Tri-colored bats were detected at $73 \%$ of points for at least one visit. The most supported covariates for estimating $p$ were visit, temperature, relative humidity, barometric pressure, and stocking (Table 3). There were 3 models for estimating $\Psi$ in the confidence set (Table 4). The most supported model included $16 \mathrm{~km}$ land cover and stocking (Table 4). None of the covariates had a coefficient confidence interval that did not include 0 (Table 5). While their coefficients' confidence intervals overlapped 0, percent forest in $16 \mathrm{~km}$, percent urban in $16 \mathrm{~km}$, and stand stocking had negative effects on $\Psi$ (Figure 1, 2, 9).

\section{DISCUSSION}

As hypothesized, big brown bat, eastern red bat, evening bat, and tri-colored bat preferred managed savanna and woodland with lower tree density than denser forest with no recent management. We found that $\Psi$ of these species was higher in areas with lower stand stocking and other vegetation structure that was found in managed savanna and woodland sites. Similarly the presence of eastern red bats/Seminole bat, evening bat, tricolored bat (eastern pipistrelle), and big brown bat was predicted by forest structure, and 
these species were found more in open savannas and woodlands than in closed forests in South Carolina (Ford et al., 2006). Occupancy of eastern red bats and tri-colored bats was also negatively related to basal area in another Missouri study (Yates and Muzika, 2006). Big brown bats, eastern red bats, northern long-eared bats, and tri-colored bats were also detected more in areas with less vegetation in South Carolina (Loeb and O'Keefe, 2006).

We also found that forest structure covariates, such as stocking, saplings/acre, poletimber/acre, sawlogs/acre, and small stems/hectare, were related to $\Psi$. Site occupancy of big brown bats, eastern red bats, and northern long-eared bats was explained in part by the stems and tree size class covariates. An increase in small stems probably indicates an open mid- and overstory that allows light to the forest floor. Big brown bats and eastern red bats had high $\Psi$ with higher numbers of small stems. Northern long-eared bat $\Psi$ decreased with increasing small stem density, showing a preference for a more closed understory. Northern long-eared bat $\Psi$ also decreased as the density of sawlogs increased, while big brown bat and eastern red bat $\Psi$ increased. High densities of sawlog-sized trees is indicative of mature, closed canopy forest but with potentially lesser understory and small tree density to clutter the midstory. An increase in poletimber/acre was associated with an increase in northern long-eared bat $\Psi$ and a decrease in both big brown bat and eastern red bat $\Psi$. An increase in poletimber indicates a more dense midstory. Site occupancy of evening bats, tri-colored bats, and northern long-eared bats was explained in part by percent stand stocking. A forest that has high percent stand stocking will be more closed than a forest with low percent stand stocking. 
Predicted $\Psi$ increased for evening bats and tri-colored bats, and decreased for northern long-eared bats, as percent stocking increased. This pattern further supports our suggestion that northern long-eared bats prefer closed canopy forest to savanna or woodland while evening bats and tri-colored bats prefer more open savanna or woodland.

Prescribed fire was an important part of managing several of the study areas that we surveyed and was also related to $\Psi$ of evening bats. The number of fires in the last 10 years was also supported in some models for northern long-eared bats. Armitage and Ober (2012) looked at bat activity in pine forests of Florida. Armitage and Ober (2012) found higher overall bat activity below the forest canopy in forests with frequent prescribed fire, which is consistent with our finding that $\Psi$ of the evening bat and northern long-eared bat increased with the number of fires in the last 10 years.

Wing morphology and call characteristics of the bats was usually, but not always, a predictor of what type of forest the bats would be using. Although tri-colored bats have a low to moderate aspect ratio (Lacki et al., 2007), the echolocation call of this species is a constant frequency (CF) call with a frequency modulated (FM) component. This type of call allows flexibility in using either in cluttered (dense forest) or non-cluttered environments, and we found that $\Psi$ of tri-colored bats decreased with an environment that was more cluttered. The echolocation call of evening bats is lower frequency than the tricolored bat, and this makes the call more suitable for an open, uncluttered environment (Lacki et al., 2007) and is consistent with their greater $\Psi$ in open savannas and woodlands. Big brown bats have the lowest frequency echolocation call of the species we studied and they have moderate aspect ratio and low wing loading (Lacki et al., 2007), 
which would indicate that the big brown bats would prefer open environments and that is consistent with the patterns in $\Psi$ we observed. Eastern red bats have moderate aspect ratio and high wing loading, and can have calls that vary greatly in frequency (Lacki et al., 2007), which might make them a clutter-adapted bat. However eastern red bats had greater $\Psi$ in environments that had less complex vertical structure.

Myotis species, like the northern long-eared bat, are morphologically adapted for more closed forest vegetation types (Owen et al., 2004; Patriquin and Barclay, 2003), which is consistent with what we found. In the Allegheny Mountains in West Virginia, Owen et al. (2004) found these bats more in closed forest types than in open upland forests. Patriquin and Barclay (2003) found northern long-eared bats preferred to forage in intact forests. This species is smaller than the big brown bat and eastern red bat, and it has a low aspect ratio and low wing loading allowing it greater maneuverability in forested sites (Lacki et al., 2007). Northern long-eared bats echolocate at very high frequencies using FM calls; this type of call is best suited to being used in cluttered spaces (Simmons and Stein, 1980).

We found support for both site and landscape scale relationships with $\Psi$, and a large landscape scale (16 km) was better for determining $\Psi$ than a smaller scale (2 km) for the eastern red bat, northern long-eared bat, evening bat, and tri-colored bat. Bats can travel long distances from their roosts to foraging areas at night. Although we did not find support for the large landscape scale for this species in our study, big brown bats travel up to $11 \mathrm{~km}$ to reach foraging sites (Arbuthnott and Brigham, 2007), and other insectivorous bats, like the spotted bat (Euderma maculatum) and Virginia big-eared bat 
(Corynorhinus townsendii virginianus), travel up to $36.3 \mathrm{~km}$ and $8.4 \mathrm{~km}$, respectively (Adam et al., 1994; Chambers et al., 2011). Yates and Muzika (2006) found landscape level support in their occupancy study of eastern red bats and northern long-eared bats, but not for tri-colored bats. Loeb and O'Keefe (2006) did not find any support for the landscape features that they looked at in their study of bat habitat use in South Carolina, however they suggested looking at other landscape features that might have support. This study and others showed that it is important to look at both a large landscape scale and site scale when determining the habitat needs of several bat species.

Our survey points were embedded in a primarily forested landscape (34\% - 92\% at the $16 \mathrm{~km}$ scale) that included a small amount of urban land cover (2\% - 12\% at the 16 $\mathrm{km}$ scale); nevertheless the percent urban in $16 \mathrm{~km}$ had an effect on some bat species. Urban areas have less vegetation and insect abundance and diversity than rural and forested areas (Faeth and Kane, 1978), and $\Psi$ of the northern long-eared, evening, and tricolored bats decreased with increasing urban land cover. However, $\Psi$ of the eastern red bat increased slightly as urban land cover increased. Eastern red bats are found in urban areas and Mager and Nelson (2001) found that urban trees are important roosts for red bats when forests have been cleared for agriculture.

Site occupancy of eastern red bats and northern long-eared bats increased with an increase in forest cover in a $16 \mathrm{~km}$ landscape; however in contrast to our hypothesis, $\Psi$ of evening bats and tri-colored bats decreased with forest cover. Other studies have shown that the northern long-eared bat roosts and forages in intact forests and that in fragmented landscapes it is constrained to using only forested areas (Broders et al., 2006; Carter and 
Feldhamer, 2005; Henderson and Broders, 2008; Sasse and Pekins, 1996; Yates and Muzika, 2006).

Evening bats had greater $\Psi$ in savannas and woodlands managed with prescribed fire compared to closed forests at a local scale, so perhaps at a landscape scale they prefer more open land cover than forested land cover. Tri-colored bats also preferred sites that had lower percent stand stocking. These species seem to prefer landscapes with a high percent of open or patchy forested areas that were not completely forested or urban. Ethier and Fahrig (2011) similarly found that the relative abundance of tri-colored bats decreased as the amount of forest cover increased in the landscape in eastern Ontario.

\section{MANAGEMENT IMPLICATIONS}

Relationships of $\Psi$ to site and landscape factors related to savanna and woodland management varied among bat species, so managers will need to consider individual species when addressing bat conservation in relation to savanna, woodland, and forest management. We suggest big brown bat, eastern red bat, evening bat, and tri-colored bat prefer managed savanna and woodland communities over closed-canopy forests in the Ozark Highlands of Missouri. So, the use of prescribed fire and forest thinning to restore and maintain these communities should benefit these species. Some species, however, like the northern long-eared bat, seem to prefer highly forested landscapes and closed canopy forest or woodlands with open understories. Therefore, managers can promote certain vegetation communities for target species, or manage for a diversity of communities within the landscape to meet the needs of the species we studied. From a 
bat conservation perspective, it is important to note that two endangered species in this region, the Indiana bat ( $M$. sodalis) and gray bat (M. grisescens), were not considered here and will likely also be an important component of conservation plans.

\section{LITERATURE CITED}

Abrams, M. D. 1992. Fire and the development of oak forests. BioScience 42: 346-353.

Adam, M. D., M. J. Lacki, and T. G. Barnes. 1994. Foraging areas and habitat use of the Virginia big-eared bat in Kentucky. Journal of Wildlife Management 58: 462-469.

Amelon, S. K. 2007. Multi-scale factors influencing detection, site occupancy and resource use by foraging bats in the Ozark Highlands of Missouri, University of Missouri, Columbia, Missouri.

Arbuthnott, D., and R. M. Brigham. 2007. The influence of a local temperature inversion on the foraging behaviour of big brown bats, Eptesicus fuscus. Acta Chiropterologica 9: 193-201.

Armitage, D. W., and H. K. Ober. 2012. The effects of prescribed fire on bat communities in the longleaf pine sandhills ecosystem. Journal of Mammalogy 93: 102-114.

Arnold, T. W. 2010. Uninformative parameters and model selection using Akaike's Information Criterion. Journal of Wildlife Management 74: 1175-1178.

Berry, N., W. O'Connor, M. W. Holderied, and G. Jones. 2004. Detection and avoidance of harp traps by echolocating bats. Acta Chiropterologica 6: 335-346.

Blehert, D. S. et al. 2009. Bat white-nose syndrome: an emerging fungal pathogen? Science 323: 227. 
Boyles, J. G., P. M. Cryan, G. F. McCracken, and T. H. Kunz. 2011. Economic importance of bats in agriculture. Science 332: 41-42.

Britzke, E. R., B. A. Slack, M. P. Armstrong, and S. C. Loeb. 2010. Effects of orientation and weatherproofing on the detection of bat echolocation calls. Journal of Fish and Wildlife Management 1: 136-141.

Broders, H. G., G. J. Forbes, S. Woodley, and I. D. Thompson. 2006. Range extent and stand selection for roosting and foraging in forest-dwelling northern long-eared bats and little brown bats in the Greater Fundy Ecosystem, New Brunswick. Journal of Wildlife Management 70: 1174-1184.

Broders, H. G., G. M. Quinn, and G. J. Forbes. 2003. Species status, and the spatial and temporal patterns of activity of bats in southwest Nova Scotia, Canada. Northeastern Naturalist 10: 383-398.

Burnham, K. P., and D. R. Anderson. 2002. Model selection and multi-model inference: a practical information-theoretic approach. Springer.

Caceres, M. C., and R. M. R. Barclay. 2000. Myotis septentrionalis. Mammalian Species 634: 1-4.

Carter, T. C., and G. A. Feldhamer. 2005. Roost tree use by maternity colonies of Indiana bats and northern long-eared bats in southern Illinois. Forest Ecology and Management 219: 259-268.

Chambers, C. L. et al. 2011. Roosts and home ranges of spotted bats (Euderma maculatum)in northern Arizona. Canadian Journal of Zoology 89: 1256-1267. 
Corben, C. 2007. Anabat. http://users.Imi.net/corben/anabat.htm Accessed February 17 2011.

Duchamp, J. E., M. Yates, R. M. Muzika, and R. K. Swihart. 2006. Estimating probabilities of detection for bat echolocation calls: An aplication of the doubleobserver method. Wildlife Society Bulletin 34: 408-412.

Ellison, L. E. 2012. Bats and wind energy - a literature synthesis and annotate bibliography: U. S. Geological Survey Open-File Report 2012-1110.

Elmore, L. W., D. A. Miller, and F. J. Vilella. 2005. Foraging area size and habitat use by red bats (Lasiurus borealis) in an intensively managed pine landscape in Mississippi. The American Midland Naturalist 153: 405-417.

Ethier, K., and L. Fahrig. 2011. Positive effects of forest fragmentation, independent of forest amount, on bat abundance in eastern Ontario, Canada. Landscape Ecology 26: 865-876.

Ethridge, M. 2009. The Ozark Highlands: U.S. Geological Fact Sheet 2009-3065.

Faeth, S. H., and T. C. Kane. 1978. Urban biogeography. Oecologia 32: 127-133.

Fenton, M. B. 1997. Science and the conservation of bats. Journal of Mammalogy 78: 114.

Ford, W. M., J. M. Menzel, M. A. Menzel, J. W. Edwards, and J. C. Kilgo. 2006. Presence and absence of bats across habitat scales in the upper Coastal Plain of South Carolina. Journal of Wildlife Management 70: 1200-1209.

Fry, J. et al. 2006. Completion of the 2006 National Land Cover Database for the Conterminous United States. PE\&RS 77: 858-864. 
Fukui, D., M. Murakami, S. Nakano, and T. Aoi. 2006. Effect of emergent aquatic insects on bat foraging in a riparian forest. The Journal of animal ecology 75: 1252-1258.

Gingrich, S. F. 1967. Measuring and evaluating stocking and stand density in upland hardwood forests in the Central States. Forest Science 13: 38-53.

Gorresen, P. M., A. C. Miles, C. M. Todd, F. J. Bonaccorso, and T. J. Weller. 2008. Assessing bat detectability and occupancy with multiple automated echolocation detectors. Journal of Mammalogy 89: 11-17.

Gorresen, P. M., and M. R. Willig. 2004. Landscape responses of bats to habitat fragmentation in Atlantic forest of Paraguay. Journal of Mammalogy 85: 688-697.

Griffin, D. R. 1971. The importance of atmospheric attenuation for the echolocation of bats (Chiroptera). Animal Behavior 19: 55-61.

Hayes, J. P. 1997. Temporal variation in activity of bats and the design of echolocationmonitoring studies. Journal of Mammalogy 78: 514-524.

Hein, C., S. Castleberry, and K. Miller. 2009. Site-occupancy of bats in relation to forested corridors. Forest Ecology and Management 257: 1200-1207.

Henderson, L. E., and H. G. Broders. 2008. Movements and Resource Selection of the Northern Long-eared Myotis (Myotis septentrionalis) in a Forest-Agriculture Landscape. Journal of Mammalogy 89: 952-963.

Kerns, J., W. P. Erickson, and E. B. Arnett. 2005. Bat and bird fatality at wind energy facilities in Pennsylvania and West Virginia. In: E. B. Arnett (ed.) Relationships between bats and wind turbines in Pennsylvania and West Virginia: An assessment of fatality search protocols, patterns of fatality, and behavioral interactions with wind turbines. A final report submitted to the Bats and Wind 
Energy Cooperative. p 24-95. Bat Conservation International, Austin, Texas, USA.

Knudsen, V. O. 1946. The propagation of sound in the atmosphere - attenuation and fluctuations. Journal of the Acoustical Society of America 18: 90-96.

Kunz, T. H. 1973. Resource utilization: temporal and spatial components of bat activity in central Iowa. Journal of Mammalogy 54: 14-32.

Kunz, T. H., and E. L. P. Anthony. 1977. On the efficiency of the Tuttle bat trap. Journal of Mammalogy 58: 309-315.

Kunz, T. H., and C. E. Brock. 1975. A comparison of mist nets and ultrasonic detectors for monitoring flight activity of bats. Journal of Mammalogy 56: 907-911.

Lacki, M. J., S. K. Amelon, and M. D. Baker. 2007. Foraging Ecology of Bats in Forests. In: M. J. Lacki, J. P. Hayes and A. Kurta (eds.) Bats in Forests: Conservation and Management. p 83-127. The Johns Hopkins University Press, Baltimore, Maryland.

Larsen, R. J. et al. 2007. Mist netting bias, species accumulation curves, and the rediscovery of two bats on Montserrat (Lesser Antilles). Acta Chiropterologica 9: 423-435.

Lawrence, B. D., and J. A. Simmons. 1982. Measurements of atmospheric attenuation at ultrasonic frequencies and the significance for echolocation by bats. Journal of the Acoustical Society of America 71: 585-590.

Livengood, K. 2003. Anabat zone of reception and the sources of variation in detection zone, University of Missouri, Columbia, Missouri. 
Loeb, S. C., and J. M. O'Keefe. 2006. Habitat use by forest bats in South Carolina in relation to local, stand, and landscape characteristics. Journal of Wildlife Management 70: 1210-1218.

Loeb, S. C., and T. A. Waldrop. 2008. Bat activity in relation to fire and fire surrogate treatments in southern pine stands. Forest Ecology and Management 255: 31853192.

Mackenzie, D. I. et al. 2006. Occupancy Estimation and Modeling. Academic Press.

Mager, K. J., and T. A. Nelson. 2001. Roost-site selection by eastern red bats (Lasiurus borealis). American Midland Naturalist 145: 120-126.

McCarty, K. 2002. Fire management for Missouri savannas and woodlands. In: Proceedings of SRM 2002: Savanna/Woodland Symposium, Kansas City, Missouri. p 40-55.

McGarigal, K., and B. J. Marks. 1994. FRAGSTATS: spatial pattern analysis program for quantifiying landscape structure.

McNab, W. H., and P. E. Avers. 1994. Ecological subregions of the United States, section descriptions Administrative Publication WO-WSA-5. U.S. Department of Agriculture, Washington, D.C., USA.

Nelson, P. M. 2002. Classification and characterization of savannas and woodlands in Missouri. In: SRM 2002: Savanna/Woodland Symposium, Kansas City, Missouri. p 9-25.

Nigh, T. A., and W. A. Schroeder. 2002. Atlas of Missouri Ecoregions. The Conservation Commission - State of Missouri. 
O'Farrell, M. J., and W. G. Bradley. 1970. Activity patterns of bats over a desert spring. Journal of Mammalogy 51: 18-26.

O'Farrell, M. J., and W. L. Gannon. 1999. A comparison of acoustic versus capture techniques for the inventory of bats. Journal of Mammalogy 80: 24-30.

Owen, S. F. et al. 2004. Bat activity in harvested and intact forest stands in the Allegheny mountains. Northern Journal of Applied Forestry 21: 154-159.

Paige, K. N. 1995. Bats and barometric pressure: conserving limited energy and tracking insects from the roost. Functional Ecology 9: 463-467.

Parsons, K. N., G. Jones, and F. Greenaway. 2003. Swarming activity of temperate zone microchiropteran bats: effects of season, time of night and weather conditions. Journal of Zoology 261: 257-264.

Patriquin, K. J., and R. M. R. Barclay. 2003. Foraging by bats in cleared, thinned and unharvested boreal forest. Journal of Applied Ecology 40: 646-657.

Patriquin, K. J., L. K. Hogberg, B. J. Chruszcz, and R. M. R. Barclay. 2003. The influence of habitat structure on the ability to detect ultrasound using bat detectors. Wildlife Society Bulletin 31: 475-481.

Roberts, S. L., J. W. van Wagtendonk, A. K. Miles, and D. A. Kelt. 2011. Effects of fire on spotted owl site occupancy in a late-successional forest. Biological Conservation 144: 610-619.

Royle, J. A., and J. D. Nichols. 2003. Estimating abundance from repeated presenceabsence data or point counts. Ecology 84: 777-790. 
Sasse, D. B., and P. J. Pekins. 1996. Summer roosting ecology of northern long-eared bats (Myotis septentrionalis) in the White Mountain National Forest. In: Bats and Forest Symposium, Victoria, British Columbia, Canada. p 91-101.

Simmons, J. A., and R. A. Stein. 1980. Acoustic imaging in bat sonar: echolocation signals and the evolution of echolocation. Journal of Comparative Physiology 135: 61-84.

Weller, T. J. 2007. Assessing population status of bats in forests: challenges and opportunities. In: M. J. Lacki, J. P. Hayes and A. Kurta (eds.) Bats in Forests: Conservation and Management. p 263-291. The Johns Hopkins University Press, Baltimore, Maryland.

Weller, T. J. 2008. Using occupancy estimation to assess the effectiveness of a regional multiple-species conservation plan: Bats in the Pacific Northwest. Biological Conservation 141: 2279-2289.

Weller, T. J., and J. A. Baldwin. 2012. Using echolocation monitoring to model bat occupancy and inform mitigations at wind energy facilities. The Journal of Wildlife Management 76: 619-631.

Wolcott, K. A., and K. Vulinec. 2012. Bat Activity at Woodland/Farmland Interfaces in Central Delaware. Northeastern Naturalist 19: 87-98.

Womack, K. M. 2011. Factors affecting insect prey and Indiana bat activity in Missouri during the maternity season, University of Missouri, Columbia, Missouri.

Yates, M. D. 2006. Detection and modeling of bat species occupancy at multiple scales across a forested landscape in southeastern Missouri, University of Missouri, Columbia, Missouri. 
Yates, M. D., and R. M. Muzika. 2006. Effect of forest structure and fragmentation on site occupancy of bat species in Missouri Ozark forests. Journal of Wildlife Management 70: 1238-1248. 
Table 1. List of study areas, ownership, year(s) sampled, and number of points sampled per site in a study of bat occupancy in the Missouri Ozark Highlands, 2010-2012.

\begin{tabular}{lrrr}
\hline Study Area & Ownership & $\begin{array}{r}\text { Year(s) } \\
\text { Sampled }\end{array}$ & $\begin{array}{r}\text { Number of } \\
\text { Points }\end{array}$ \\
\hline Lead Mine Conservation Area & MDC & 2010 & 9 \\
Sunklands Conservation Area & MDC & 2010 & 9 \\
Little Black Conservation Area & MDC & 2011 & 8 \\
Ha Ha Tonka State Park & DNR & 2011 & 10 \\
Lake of the Ozarks State Park & DNR & 2011 & 16 \\
Knob Noster State Park & DNR & 2011 & 12 \\
Rocky Creek Conservation Area & MDC & 2011 & 4 \\
Western Star Flatwoods & MTNF & 2011 & 10 \\
Caney Mountain Conservation Area & MDC & 2011 & 15 \\
Drury-Mincy Conservation Area & MDC & 2011 & 11 \\
Bluff Springs Conservation Area & MDC & 2011 & 8 \\
Indian Trail Conservation Area & MDC & 2011 & 12 \\
St. Joe State Park & DNR & 2011 & 16 \\
White Ranch Conservation Area & MDC & 2011 & 7 \\
Chilton Creek & TNC & 2011 & 7 \\
Cuivre River State Park & DNR & 2012 & 19 \\
Handy & MTNF & 2012 & 16 \\
Cane Ridge & MTNF & 2012 & 14 \\
Peck Ranch Conservation Area & MDC & 2012 & 28 \\
St. Francois State Park & DNR & 2012 & 14 \\
Mark Twain Glade Top & MTNF & 2012 & 13 \\
Ava & MTNF & 2012 & 12 \\
Big Creek & MTNF & 2012 & 18 \\
Three Sisters & MTNF & 2012 & 10 \\
Bennett Springs State Park & DNR & 2010,2012 & 19 \\
Pine Knot & MTNF & 2011,2012 & 25 \\
\hline
\end{tabular}


Table 2. We present the minimum, maximum, mean, and standard error (SE) of each continuous covariate that was used in an occupancy study of 5 bat species in the Missouri Ozark Highlands, 2010-2012.

\begin{tabular}{lrrrr}
\hline Covariate $^{*}$ & Minimum & Maximum & Mean & SE \\
\hline PINEBA & 0.00 & 105.90 & 11.43 & 24.82 \\
STANDSTOCK & 0.00 & 177.93 & 84.73 & 40.26 \\
FIRE10YRS & 0.00 & 8.00 & 1.76 & 1.74 \\
sapl_ac & 0.00 & 3886.94 & 386.99 & 704.09 \\
pole_ac & 0.00 & 617.15 & 126.29 & 140.03 \\
sawl_ac & 0.00 & 343.13 & 53.51 & 64.67 \\
stems_HA & 0.00 & 66817.93 & 6316.16 & 16645.55 \\
dist2water & 1.81 & 548.13 & 238.16 & 143.27 \\
dist2road & 2.12 & 1992.91 & 467.70 & 460.50 \\
2kforest & 59.70 & 97.91 & 87.67 & 8.53 \\
2kurban & 0.55 & 21.31 & 4.02 & 3.52 \\
16kforest & 24.18 & 92.15 & 70.19 & 15.94 \\
16kurban & 2.31 & 11.51 & 5.23 & 2.40 \\
\hline
\end{tabular}

${ }^{*}$ PINEBA $=$ pine basal area, STANDSTOCK $=$ percent tree stocking, FIRE10YRS $=$ the number of fires in the last 10 years, sapl_ac = saplings per acre, pole_ac = poletimber per acre, sawl_ac = sawlogs per acre, stems_HA = small stems per hectare, dist2water $=$ distance to nearest water in meters, dist2road $=$ distance to nearest road in meters, $2 \mathrm{kforest}=$ percent forest in a $2 \mathrm{~km}$ radius around the point, $2 \mathrm{kurban}=$ percent urban in a $2 \mathrm{~km}$ radius around the point, 16kforest = percent forest in a $16 \mathrm{~km}$ radius around the point, $16 \mathrm{kurban}=$ percent urban in a $16 \mathrm{~km}$ radius around the point 
Table 3. The most supported site occupancy models for the probability of detection $(p)$, while holding occupancy $(\Psi)$ effects constant, based on acoustic surveys of 5 bat species in the Missouri Ozark Highlands, 2010-2012. We present number of model parameters (k), log likelihood (LogLik), Akaike's Information Criterion (AIC), delta AIC ( $\triangle \mathrm{AIC}$ ), and AIC weight $\left(w_{i}\right)$ for each model.

\begin{tabular}{|c|c|c|c|c|c|}
\hline Model by species & $\mathrm{k}$ & LogLik & AIC & $\Delta \mathrm{AIC}$ & $w_{i}$ \\
\hline \multicolumn{6}{|l|}{ Big brown bat } \\
\hline$\Psi$ (habitat),p(v,weather,date,stocking) & 12 & 1532.03 & 1556.03 & 0 & 0.554 \\
\hline \multicolumn{6}{|l|}{ Eastern red bat } \\
\hline$\Psi$ (habitat),p(weather,date,stocking) & 9 & 1493.93 & 1511.93 & 0 & 0.519 \\
\hline \multicolumn{6}{|l|}{ Northern long-eared bat } \\
\hline$\Psi$ (habitat),p(v,weather, water) & 11 & 1523.6 & 1545.6 & 0 & 0.4592 \\
\hline \multicolumn{6}{|l|}{ Evening bat } \\
\hline$\Psi($ habitat),p(date,stocking) & 6 & 793.28 & 805.28 & 0 & 0.2709 \\
\hline \multicolumn{6}{|l|}{ Tri-colored bat } \\
\hline$\Psi$ (habitat),p(v,weather,stocking) & 11 & 1648.12 & 1670.12 & 0 & 0.2818 \\
\hline
\end{tabular}


Table 4. The most supported site occupancy models $(\Delta \mathrm{AIC}<4)$ for the probability of site occupancy ( $\Psi$ ) for 5 bat species in the Missouri Ozark Highlands, 2010-2012. We present number of model parameters (k), log likelihood (LogLik), Akaike's Information Criterion (AIC), delta AIC ( $\triangle \mathrm{AIC})$, and AIC weight $\left(w_{i}\right)$ for each model.

\begin{tabular}{|c|c|c|c|c|c|}
\hline Model by species & $\mathrm{k}$ & LogLike & AIC & $\Delta \mathrm{AIC}$ & $w_{i}$ \\
\hline \multicolumn{6}{|l|}{ Big brown bat } \\
\hline$\Psi$ (stems,conba), $p$ (v,weather,date,stocking) & 15 & 1524.19 & 1554.19 & 0 & 0.3162 \\
\hline$\Psi$ (stems), $p$ (v,weather,date,stocking) & 14 & 1526.99 & 1554.99 & 0.8 & 0.212 \\
\hline$\Psi$ (conba), $p$ (v,weather,date,stocking) & 11 & 1534.31 & 1556.31 & 2.12 & 0.1096 \\
\hline$\Psi(),$.$p (v,weather,date,stocking)$ & 10 & 1536.78 & 1556.78 & 2.59 & 0.0866 \\
\hline \multicolumn{6}{|l|}{ Eastern red bat } \\
\hline$\Psi$ (16klandcover,stems,road,water),p(weather,date,stocking) & 15 & 1478.39 & 1508.39 & 0 & 0.4412 \\
\hline$\Psi$ (stems,road,water), $p$ (weather,date,stocking) & 13 & 1483.32 & 1509.32 & 0.93 & 0.2771 \\
\hline$\Psi($ 16klandcover,stems,road),p(weather,date,stocking) & 14 & 1482.52 & 1510.52 & 2.13 & 0.1521 \\
\hline \multicolumn{6}{|l|}{ Northern long-eared bat } \\
\hline$\Psi$ (stems,16klandcover), $p$ (v,weather,water) & 15 & 1484.43 & 1514.43 & 0 & 0.5681 \\
\hline$\Psi$ (global),p(v,weather,water) & 20 & 1475.01 & 1515.01 & 0.58 & 0.4251 \\
\hline \multicolumn{6}{|l|}{ Evening bat } \\
\hline$\Psi$ (16klandcover,stocking,fire),p(date,stocking) & 8 & 759.38 & 775.38 & 0 & 0.5588 \\
\hline \multicolumn{6}{|l|}{ Tri-colored bat } \\
\hline$\Psi$ (16klandcover,stocking), $p$ (v,weather,stocking) & 12 & 1646.28 & 1670.28 & 0 & 0.3257 \\
\hline$\Psi$ (stocking), $p$ (v,weather,stocking) & 10 & 1652.52 & 1672.52 & 2.24 & 0.1063 \\
\hline$\Psi$ (16klandcover), $p$ (v,weather,stocking) & 11 & 1650.62 & 1672.62 & 2.34 & 0.1011 \\
\hline
\end{tabular}


Table 5. Model averaged parameter estimates, unconditional standard errors (unconditional SE), and the upper and lower bounds for the 95\% confidence intervals in a study of site occupancy of 5 bat species in the Missouri Ozark Highlands, 2010-2012.

\begin{tabular}{|c|c|c|c|c|}
\hline & & unconditional & lower & upper \\
\hline Variables by species & Coefficient & SE & bound & bound \\
\hline \multicolumn{5}{|l|}{ Big brown bat } \\
\hline sapl_ac & 0.1816 & 0.2647 & -0.3371 & 0.7004 \\
\hline pole_ac & -0.1120 & 0.2445 & -0.5913 & 0.3672 \\
\hline sawl_ac & 0.1414 & 0.2804 & -0.4081 & 0.6910 \\
\hline stems_HA & 1.0378 & 0.8877 & -0.7021 & 2.7778 \\
\hline PINEBA & 0.2860 & 0.4492 & -0.5945 & 1.1665 \\
\hline \multicolumn{5}{|l|}{ Eastern red bat } \\
\hline 16kforest & 0.6685 & 0.3493 & -0.0161 & 1.3530 \\
\hline 16kurban & 0.2736 & 0.2911 & -0.2969 & 0.8441 \\
\hline sapl_ac & -0.0408 & 0.2963 & -0.6216 & 0.5399 \\
\hline pole_ac & -0.5417 & 0.2847 & -1.0996 & 0.0163 \\
\hline sawl_ac & -0.1887 & 0.2322 & -0.6438 & 0.2665 \\
\hline stems_HA & 5.3647 & 2.7135 & 0.0462 & 10.6832 \\
\hline dist2road & -0.6512 & 0.2137 & -1.0701 & -0.2324 \\
\hline dist2water & 0.1434 & 0.2349 & -0.3171 & 0.6039 \\
\hline \multicolumn{5}{|c|}{ Northern long-eared bat } \\
\hline PINEBA & -0.0042 & 0.0068 & -0.0175 & 0.0091 \\
\hline STANDSTOCK & 0.0061 & 0.0073 & -0.0083 & 0.0204 \\
\hline FIRE10YRS & 0.0468 & 0.0742 & -0.0988 & 0.1923 \\
\hline sapl_ac & -0.0005 & 0.0004 & -0.0014 & 0.0003 \\
\hline pole_ac & 0.0005 & 0.0012 & -0.0018 & 0.0028 \\
\hline sawl_ac & -0.0022 & 0.0024 & -0.0070 & 0.0025 \\
\hline dist2water & -0.0002 & 0.0004 & -0.0010 & 0.0007 \\
\hline dist2road & 0.0002 & 0.0003 & -0.0004 & 0.0007 \\
\hline 16kforest & 0.0264 & 0.0094 & 0.0080 & 0.0448 \\
\hline 16kurban & -0.2161 & 0.0757 & -0.3645 & -0.0677 \\
\hline stems_HA & 0.0000 & 0.0001 & -0.0002 & 0.0002 \\
\hline \multicolumn{5}{|l|}{ Evening bat } \\
\hline 16kforest & -0.0328 & 0.0067 & -0.0459 & -0.0196 \\
\hline 16kurban & -0.2161 & 0.0807 & -0.3741 & -0.0580 \\
\hline STANDSTOCK & -0.0174 & 0.0039 & -0.0250 & -0.0098 \\
\hline FIRE10YRS & 0.2676 & 0.0834 & 0.1042 & 0.4310 \\
\hline \multicolumn{5}{|l|}{ Tri-colored bat } \\
\hline 16kforest & -0.0221 & 0.0117 & -0.0450 & 0.0008 \\
\hline 16kurban & -0.1310 & 0.0818 & -0.2913 & 0.0294 \\
\hline STANDSTOCK & -0.0066 & 0.0039 & -0.0142 & 0.0010 \\
\hline
\end{tabular}



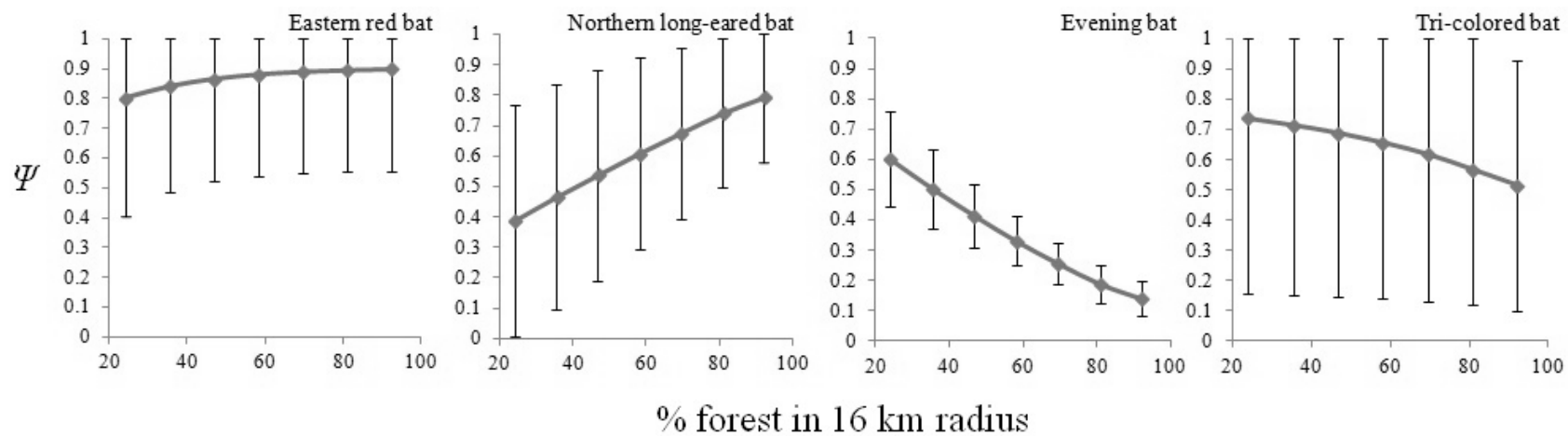

Figure 1. Probability of occupancy ( $\Psi$ ) across the range of percent forest in a $16 \mathrm{~km}$ radius for the eastern red bat, northern long-eared bat, evening bat, and tri-colored bat in the Missouri Ozark Highlands, 2010-2012. 

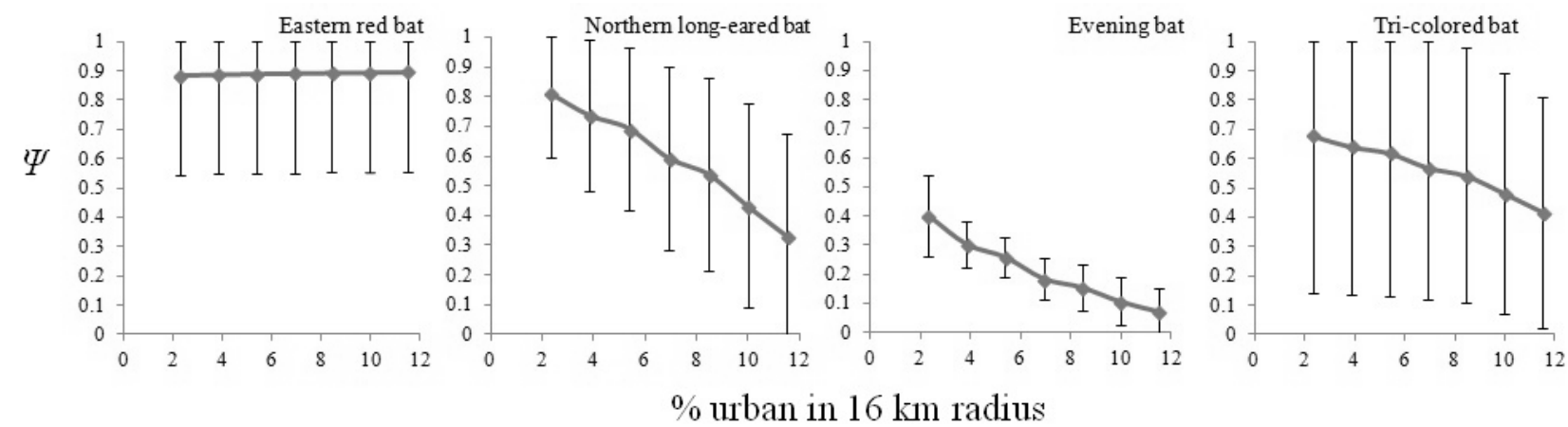

Figure 2. Probability of occupancy ( $\Psi$ ) across the range of percent urban land use in a 16 $\mathrm{km}$ radius for the eastern red bat, northern long-eared bat, evening bat, and tri-colored bat in the Missouri Ozark Highlands, 2010-2012. 

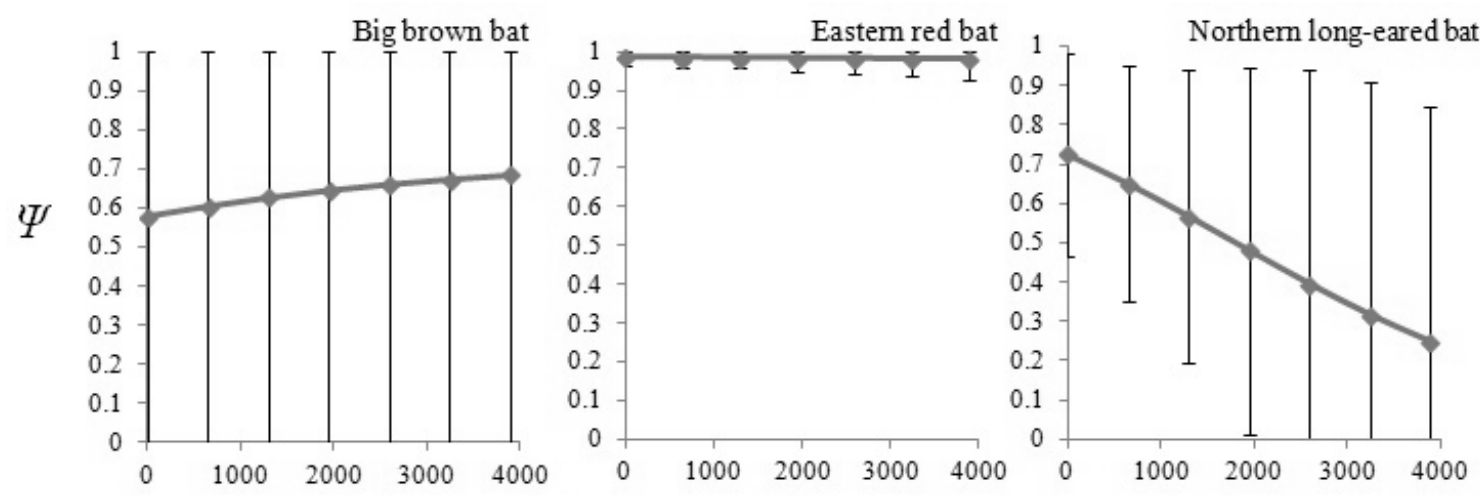

Saplings/acre

Figure 3. Probability of occupancy $(\Psi)$ across the range of saplings per acre for the big brown bat, eastern red bat, and northern long-eared bat in the Missouri Ozark Highlands, 2010-2012. 

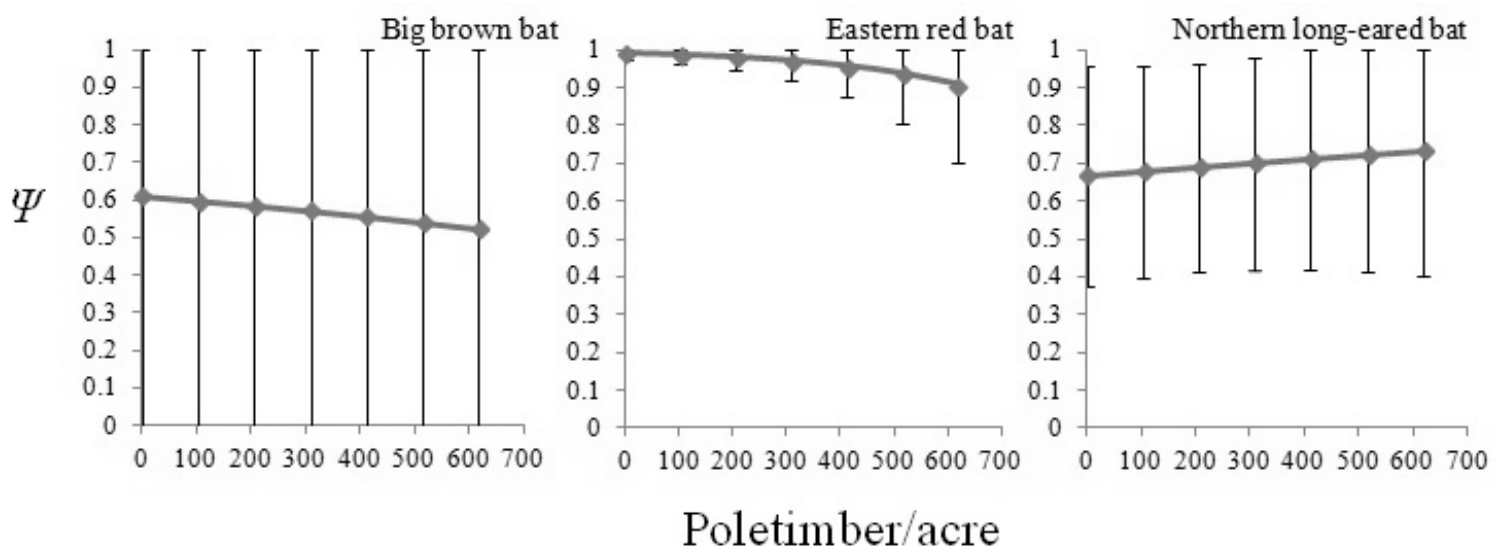

Figure 4. Probability of occupancy $(\Psi)$ across the range of poletimber per acre for the big brown bat, eastern red bat, and northern long-eared bat in the Missouri Ozark Highlands, 2010-2012. 

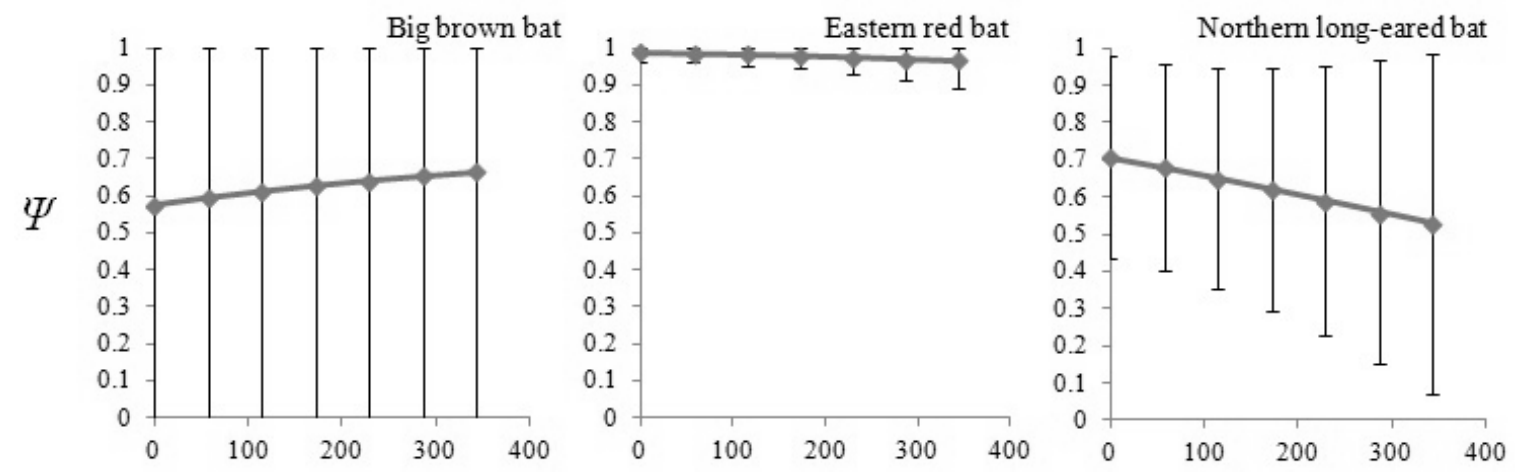

Sawlogs/acre

Figure 5. Probability of occupancy $(\Psi)$ across the range of sawlogs per acre for the big brown bat, eastern red bat, and northern long-eared bat in the Missouri Ozark Highlands, 2010-2012. 

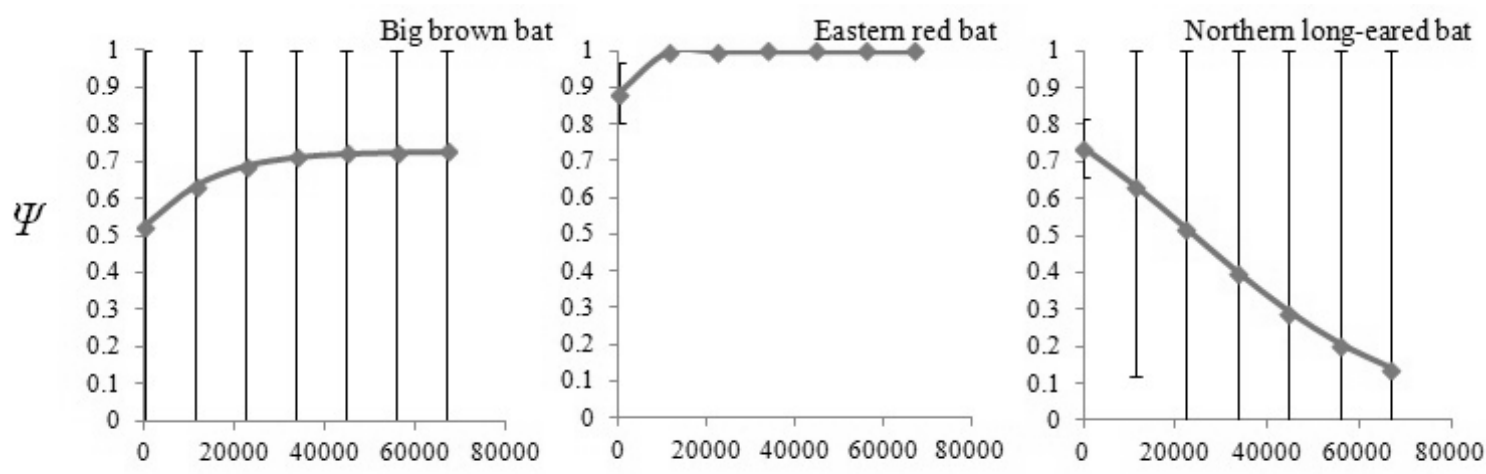

\section{Small stems/hectare}

Figure 6. Probability of occupancy $(\Psi)$ across the range of small stems per hectare for the big brown bat, eastern red bat, and northern long-eared bat in the Missouri Ozark Highlands, 2010-2012. 


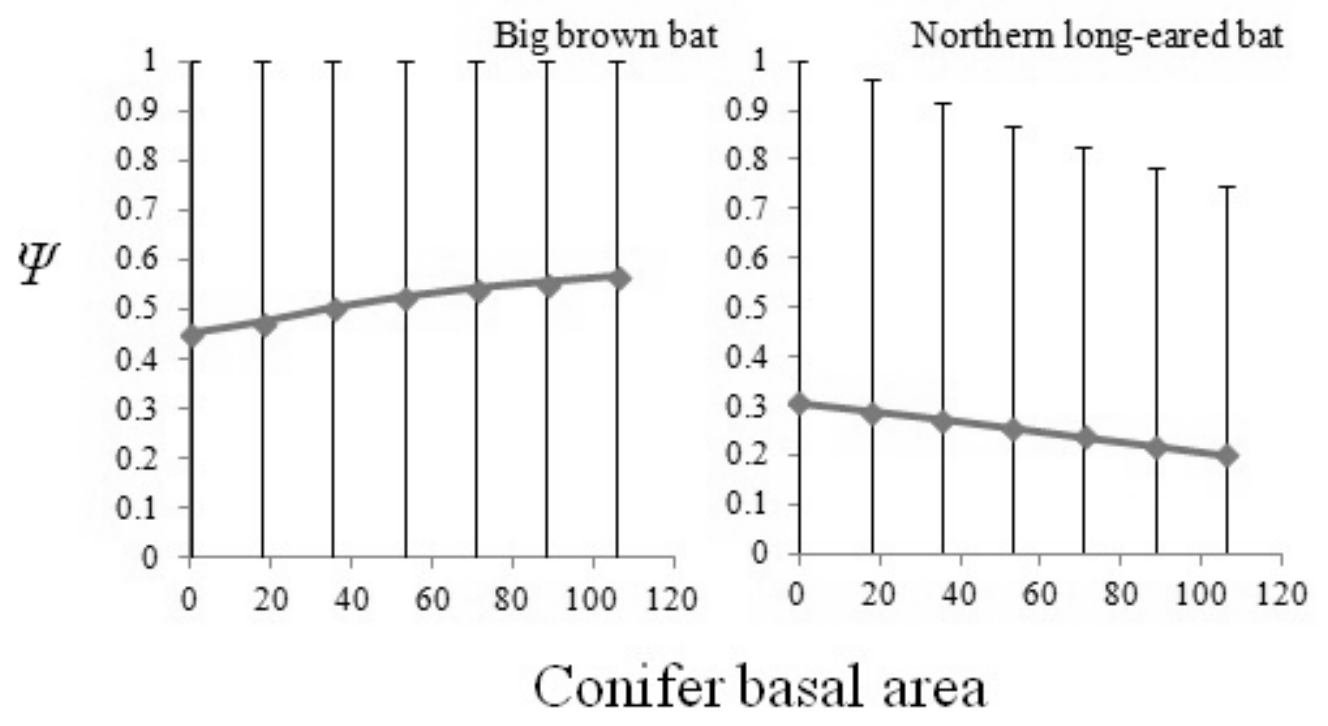

Figure 7. Probability of occupancy $(\Psi)$ across the range of conifer basal area for the big brown bat and northern long-eared bat in the Missouri Ozark Highlands, 2010-2012. 


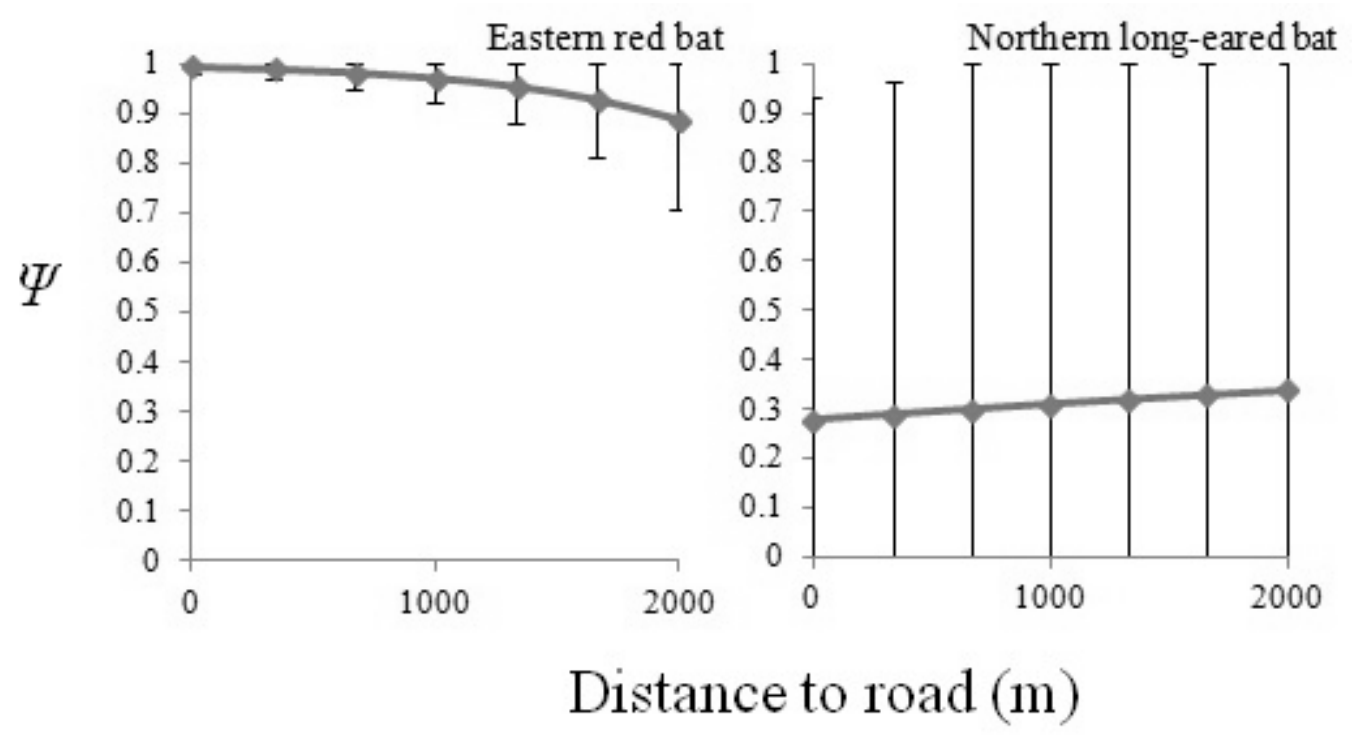

Figure 8. Probability of occupancy $(\Psi)$ across the range of distance to road in meters for the eastern red bat and northern long-eared bat in the Missouri Ozark Highlands, 20102012. 

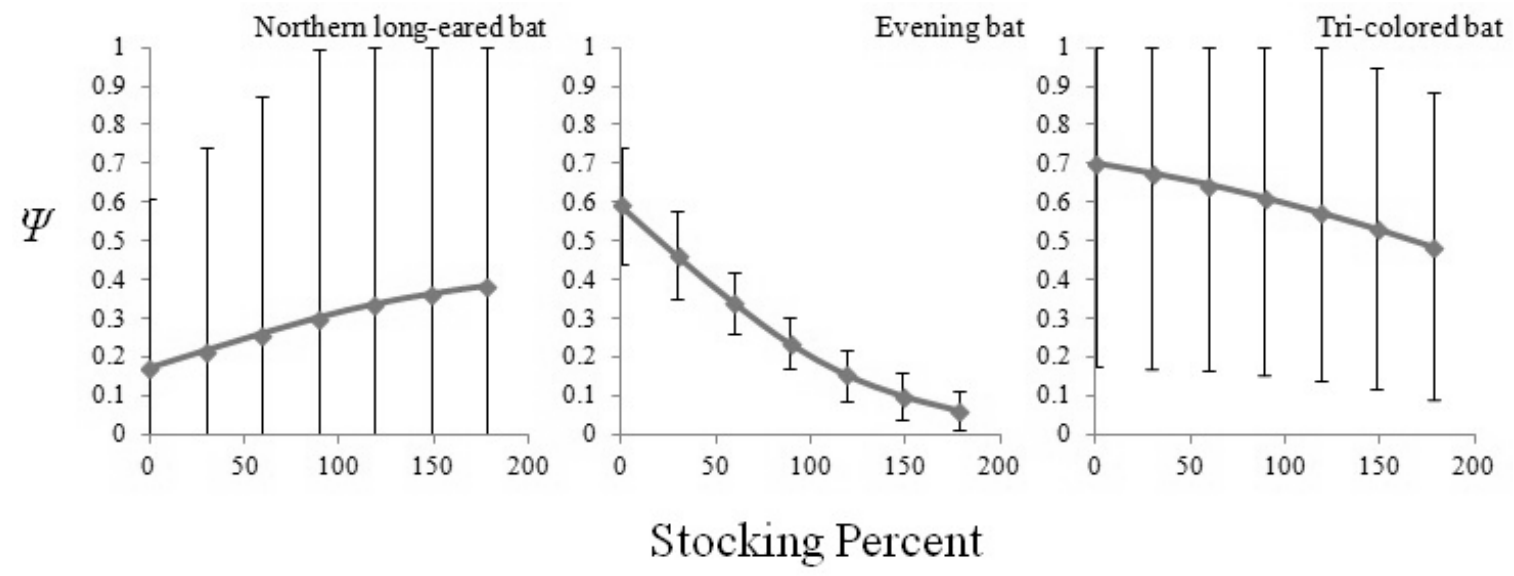

Figure 9. Probability of occupancy $(\Psi)$ across the range of percent stand stocking for the northern long-eared bat, evening bat, and tri-colored bat in the Missouri Ozark Highlands, 2010-2012. 


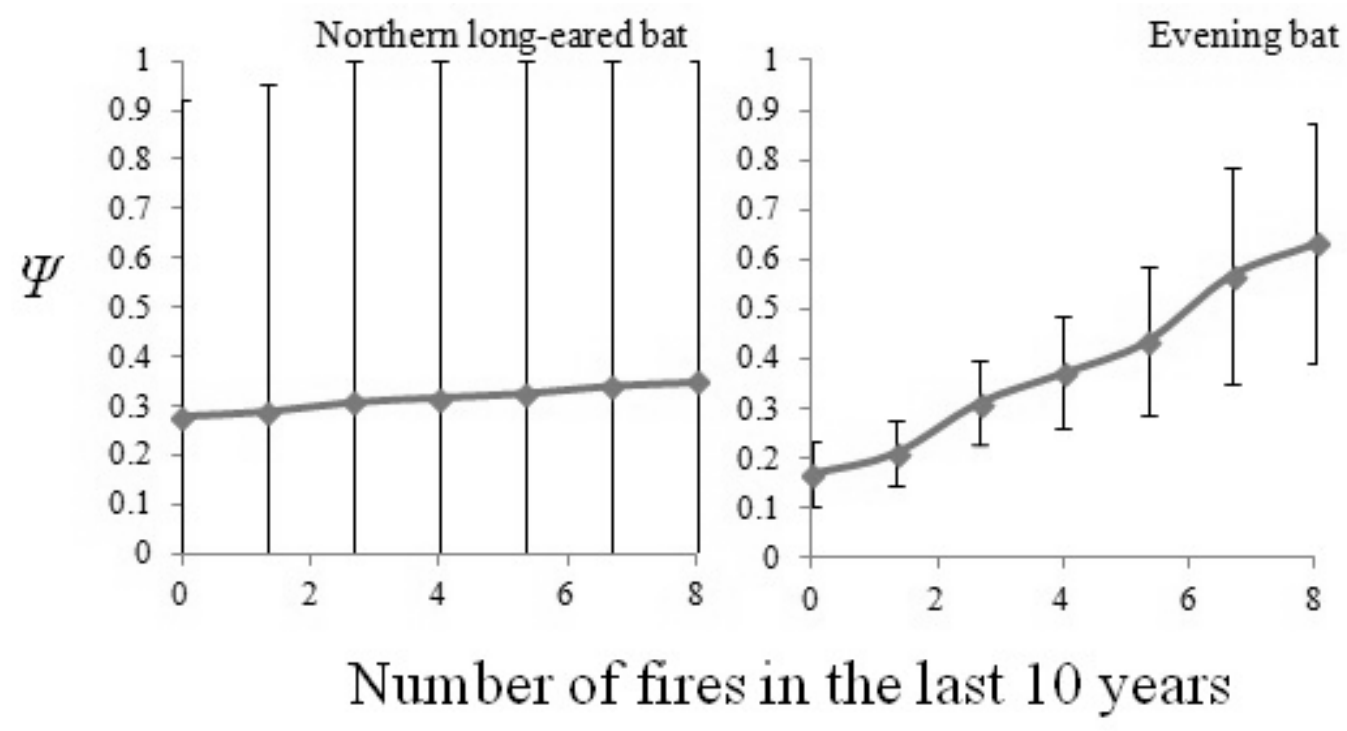

Figure 10. Probability of occupancy ( $\Psi$ ) across the range of the number of fires in the last 10 years for the northern long-eared bat and evening bat in the Missouri Ozark Highlands, 2010-2012. 


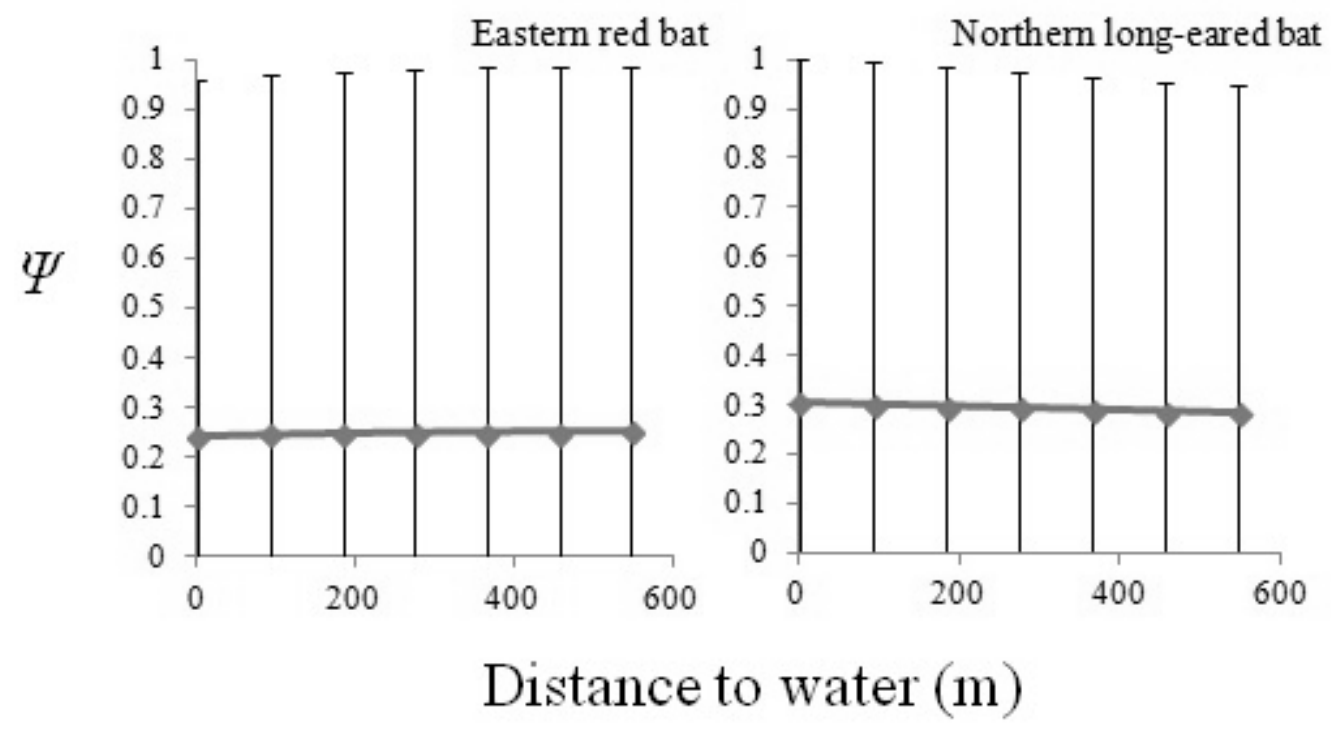

Figure 11. Probability of occupancy ( $\Psi$ ) across the range of distance to nearest water in meters for the eastern red bat and northern long-eared bat in the Missouri Ozark Highlands, 2010-2012. 


\section{APPENDIX}

Appendix. All models for probability of occupancy $(\Psi)$. We present number of parameters (k), log likelihood (LogLik), Akaike's Information Criterion (AIC), delta AIC $(\triangle \mathrm{AIC})$, and AIC weight $\left(w_{i}\right)$ for each model.

\begin{tabular}{|c|c|c|c|c|c|}
\hline Model by species & $\mathrm{k}$ & LogLike & AIC & $\Delta \mathrm{AIC}$ & $w_{i}$ \\
\hline \multicolumn{6}{|l|}{ Big brown bat } \\
\hline$\Psi($ stems,conba), $p$ (v,weather,date,stocking) & 15 & 1524.19 & 1554.19 & 0 & 0.3162 \\
\hline$\Psi$ (stems), $p$ (v,weather,date,stocking) & 14 & 1526.99 & 1554.99 & 0.8 & 0.212 \\
\hline$\Psi$ (conba),p(v,weather,date,stocking) & 11 & 1534.31 & 1556.31 & 2.12 & 0.1096 \\
\hline$\Psi(),$.$p (v,weather,date,stocking)$ & 10 & 1536.78 & 1556.78 & 2.59 & 0.0866 \\
\hline$\Psi(16$ klandcover),p(v,weather,date,stocking) & 12 & 1532.91 & 1556.91 & 2.72 & 0.0812 \\
\hline$\Psi$ (water), $p$ (v,weather,date,stocking) & 11 & 1535.96 & 1557.96 & 3.77 & 0.048 \\
\hline$\Psi$ (road),p(v,weather,date,stocking) & 11 & 1536.53 & 1558.53 & 4.34 & 0.0361 \\
\hline$\Psi$ (stocking), $p$ (v,weather,date,stocking) & 11 & 1536.74 & 1558.74 & 4.55 & 0.0325 \\
\hline$\Psi($ fire $), p$ (v,weather,date,stocking) & 11 & 1536.75 & 1558.75 & 4.56 & 0.0323 \\
\hline$\Psi$ (2klandcover), $p$ (v,weather,date,stocking) & 12 & 1535.27 & 1559.27 & 5.08 & 0.0249 \\
\hline$\Psi$ (global),p(v,weather,date,stocking) & 21 & 1517.66 & 1559.66 & 5.47 & 0.0205 \\
\hline \multicolumn{6}{|l|}{ Eastern red bat } \\
\hline$\Psi(16$ klandcover,stems,road,water),p(weather,date,stocking) & 15 & 1478.39 & 1508.39 & 0 & 0.4412 \\
\hline$\Psi$ (stems,road,water),p(weather,date,stocking) & 13 & 1483.32 & 1509.32 & 0.93 & 0.2771 \\
\hline$\Psi(16$ klandcover,stems,road),p(weather,date,stocking) & 14 & 1482.52 & 1510.52 & 2.13 & 0.1521 \\
\hline$\Psi$ (global), $p$ (weather,date,stocking) & 18 & 1476.79 & 1512.79 & 4.4 & 0.0489 \\
\hline$\Psi$ (stems,road), $p$ (weather,date,stocking) & 12 & 1489.72 & 1513.72 & 5.33 & 0.0307 \\
\hline$\Psi$ (stems, water),p(weather,date,stocking) & 12 & 1490.26 & 1514.26 & 5.87 & 0.0234 \\
\hline$\Psi$ (16klandcover,stems, water),p(weather,date,stocking) & 14 & 1486.78 & 1514.78 & 6.39 & 0.0181 \\
\hline$\Psi$ (16klandcover,stems),p(weather,date,stocking) & 13 & 1492.01 & 1518.01 & 9.62 & 0.0036 \\
\hline$\Psi$ (stems),p(weather,date,stocking) & 11 & 1497.08 & 1519.08 & 10.69 & 0.0021 \\
\hline$\Psi(16$ klandcover,road),p(weather,date,stocking) & 10 & 1501.37 & 1521.37 & 12.98 & 0.0007 \\
\hline$\Psi$ (road,water), $p$ (weather,date,stocking) & 9 & 1503.65 & 1521.65 & 13.26 & 0.0006 \\
\hline$\Psi$ (16klandcover,road,water),p(weather,date,stocking) & 11 & 1499.83 & 1521.83 & 13.44 & 0.0005 \\
\hline$\Psi$ (stocking), $p$ (weather,date,stocking) & 8 & 1506.07 & 1522.07 & 13.68 & 0.0005 \\
\hline$\Psi$ (road), $p$ (weather,date,stocking) & 8 & 1507.04 & 1523.04 & 14.65 & 0.0003 \\
\hline$\Psi$ (water),p(weather,date,stocking) & 8 & 1509.08 & 1525.08 & 16.69 & 0.0001 \\
\hline$\Psi$ (16klandcover,water),p(weather,date,stocking) & 10 & 1506.01 & 1526.01 & 17.62 & 0.0001 \\
\hline$\Psi(16$ klandcover),p(weather,date,stocking) & 9 & 1508.53 & 1526.53 & 18.14 & 0.0001 \\
\hline$\Psi(),$.$p (weather,date,stocking)$ & 7 & 1513.19 & 1527.19 & 18.8 & 0 \\
\hline$\Psi$ (fire), $p$ (weather,date,stocking) & 8 & 1512.62 & 1528.62 & 20.23 & 0 \\
\hline$\Psi$ (conba), $p$ (weather,date,stocking) & 8 & 1512.71 & 1528.71 & 20.32 & 0 \\
\hline
\end{tabular}




\begin{tabular}{|c|c|c|c|c|c|}
\hline Model by species & $\mathrm{k}$ & LogLike & AIC & $\Delta \mathrm{AIC}$ & $w_{i}$ \\
\hline$\Psi$ (2klandcover), $p$ (weather,date,stocking) & 9 & 1512.32 & 1530.32 & 21.93 & 0 \\
\hline \multicolumn{6}{|l|}{ Northern long-eared bat } \\
\hline$\Psi$ (stems,16klandcover), $p$ (v,weather,water) & 15 & 1484.43 & 1514.43 & 0 & 0.5681 \\
\hline$\Psi$ (global),p(v,weather,water) & 20 & 1475.01 & 1515.01 & 0.58 & 0.4251 \\
\hline$\Psi$ (16klandcover), $p$ (v,weather,water) & 11 & 1501.28 & 1523.28 & 8.85 & 0.0068 \\
\hline$\Psi$ (2klandcover), $p$ (v,weather,water) & 11 & 1510.56 & 1532.56 & 18.13 & 0.0001 \\
\hline$\Psi$ (stems),p(v,weather,water) & 13 & 1515.54 & 1541.54 & 27.11 & 0 \\
\hline$\Psi(),$.$p (v,weather,water)$ & 9 & 1529.88 & 1547.88 & 33.45 & 0 \\
\hline$\Psi$ (fire),p(v,weather,water) & 10 & 1528.04 & 1548.04 & 33.61 & 0 \\
\hline$\Psi$ (stocking), $p$ (v,weather,water) & 10 & 1528.28 & 1548.28 & 33.85 & 0 \\
\hline$\Psi($ conba $), p$ (v,weather, water) & 10 & 1528.64 & 1548.64 & 34.21 & 0 \\
\hline$\Psi$ (water), $p$ (v,weather,water) & 10 & 1528.98 & 1548.98 & 34.55 & 0 \\
\hline$\Psi(\mathrm{road}), p$ (v,weather,water) & 10 & 1529.6 & 1549.6 & 35.17 & 0 \\
\hline \multicolumn{6}{|l|}{ Evening bat } \\
\hline$\Psi(16$ klandcover,stocking,fire),p(date,stocking) & 8 & 759.38 & 775.38 & 0 & 0.5588 \\
\hline$\Psi(16 k l a n d c o v e r$, stocking,fire,conba),p(date,stocking) & 9 & 758.75 & 776.75 & 1.37 & 0.2817 \\
\hline$\Psi$ (stocking,fire),p(date,stocking) & 6 & 767.52 & 779.52 & 4.14 & 0.0705 \\
\hline$\Psi$ (stocking,fire,conba),p(date,stocking) & 7 & 766.22 & 780.22 & 4.84 & 0.0497 \\
\hline$\Psi$ (global),p(date,stocking) & 15 & 751.34 & 781.34 & 5.96 & 0.0284 \\
\hline$\Psi$ (16klandcover,stocking),p(date,stocking) & 7 & 770.26 & 784.26 & 8.88 & 0.0066 \\
\hline$\Psi(16$ klandcover,stocking,conba),p(date,stocking) & 8 & 769.7 & 785.7 & 10.32 & 0.0032 \\
\hline$\Psi(16$ klandcover,conba,fire),p(date,stocking) & 8 & 773.33 & 789.33 & 13.95 & 0.0005 \\
\hline$\Psi$ (16klandcover,fire),p(date,stocking) & 7 & 776.39 & 790.39 & 15.01 & 0.0003 \\
\hline$\Psi$ (stocking),p(date,stocking) & 5 & 781.29 & 791.29 & 15.91 & 0.0002 \\
\hline$\Psi($ stocking,conba),p(date,stocking) & 6 & 780.15 & 792.15 & 16.77 & 0.0001 \\
\hline$\Psi($ fire,conba),p(date,stocking) & 6 & 782.94 & 794.94 & 19.56 & 0 \\
\hline$\Psi($ fire $), p$ (date,stocking) & 5 & 787.56 & 797.56 & 22.18 & 0 \\
\hline$\Psi(16$ klandcover,conba),p(date,stocking) & 7 & 786.01 & 800.01 & 24.63 & 0 \\
\hline$\Psi(16 \mathrm{klandcover}), p$ (date,stocking) & 6 & 788.91 & 800.91 & 25.53 & 0 \\
\hline$\Psi$ (stems),p(date,stocking) & 8 & 786.79 & 802.79 & 27.41 & 0 \\
\hline$\Psi$ (conba),p(date,stocking) & 5 & 800.51 & 810.51 & 35.13 & 0 \\
\hline$\Psi(),$.$p (date,stocking)$ & 4 & 804.68 & 812.68 & 37.3 & 0 \\
\hline$\Psi($ road),p(date,stocking) & 5 & 803.97 & 813.97 & 38.59 & 0 \\
\hline$\Psi$ (water),p(date,stocking) & 5 & 804.39 & 814.39 & 39.01 & 0 \\
\hline$\Psi$ (2klandcover),p(date,stocking) & 6 & 803.58 & 815.58 & 40.2 & 0 \\
\hline \multicolumn{6}{|l|}{ Tri-colored bat } \\
\hline$\Psi$ (16klandcover,stocking),p(v,weather,stocking) & 12 & 1646.28 & 1670.28 & 0 & 0.3257 \\
\hline$\Psi(16$ klandcover,stocking,fire), $p$ (v,weather,stocking) & 13 & 1645.17 & 1671.17 & 0.89 & 0.2087 \\
\hline
\end{tabular}




\begin{tabular}{|c|c|c|c|c|c|}
\hline Model by species & $\mathrm{k}$ & LogLike & AIC & $\Delta \mathrm{AIC}$ & $w_{i}$ \\
\hline$\Psi$ (stocking),p(v,weather,stocking) & 10 & 1652.52 & 1672.52 & 2.24 & 0.1063 \\
\hline$\Psi$ (stocking,fire),p(v,weather,stocking) & 11 & 1650.59 & 1672.59 & 2.31 & 0.1026 \\
\hline$\Psi(16 \mathrm{klandcover}), p$ (v,weather,stocking) & 11 & 1650.62 & 1672.62 & 2.34 & 0.1011 \\
\hline$\Psi$ (16klandcover,fire),p(v,weather,stocking) & 12 & 1649.15 & 1673.15 & 2.87 & 0.0775 \\
\hline$\Psi($ fire $), p(\mathrm{v}$,weather,stocking) & 10 & 1656.15 & 1676.15 & 5.87 & 0.0173 \\
\hline$\Psi$ (global),p(v,weather,stocking) & 20 & 1636.56 & 1676.56 & 6.28 & 0.0141 \\
\hline$\Psi(),. p($ v,weather,stocking) & 9 & 1659.02 & 1677.02 & 6.74 & 0.0112 \\
\hline$\Psi$ (2klandcover),p(v,weather,stocking) & 11 & 1655.18 & 1677.18 & 6.9 & 0.0103 \\
\hline$\Psi($ road $), p$ (v,weather,stocking) & 10 & 1657.26 & 1677.26 & 6.98 & 0.0099 \\
\hline$\Psi$ (stems),p(v,weather,stocking) & 13 & 1652.41 & 1678.41 & 8.13 & 0.0056 \\
\hline$\Psi$ (water),p(v,weather,stocking) & 10 & 1658.54 & 1678.54 & 8.26 & 0.0052 \\
\hline$\Psi$ (conba),p(v,weather,stocking) & 10 & 1658.86 & 1678.86 & 8.58 & 0.0045 \\
\hline
\end{tabular}

